\title{
LA UNIÓN EUROPEA Y LOS ESTADOS MIEMBROS EN LOS PROCEDIMIENTOS DE ARREGLO JURISDICCIONAL DE CONTROVERSIAS DE LA CNUDM
}

\author{
ROSARIO OJINAGA RUIZ \\ ojinagar@unican.es
}

Cómo citar/Citation

Ojinaga Ruiz, R. (2016).

La Unión Europea y los Estados miembros en los procedimientos de arreglo jurisdiccional de controversias de la CNUDM. Revista de Derecho Comunitario Europeo, 55, 977-1018. doi: http://dx.doi.org/10.18042/cepc/rdce.55.06

\section{Resumen}

La Unión Europea está incrementando su participación en los sistemas de arreglo de controversias en un contexto caracterizado por la proliferación de jurisdicciones internacionales. En particular, el sistema de arreglo de controversias de la Convención de las Naciones Unidas sobre el Derecho del Mar (CNUDM) incluye previsiones específicas sobre la participación de la Unión Europea en los procedimientos de arreglo jurisdiccional contemplados en la sección 2 de la parte XV, de interés para el estudio de esa tendencia. Más concretamente, se observa un incremento relativo de la práctica de la UE y los Estados miembros ante el Tribunal Internacional de Derecho del Mar (TIDM). Así, recientemente, el primer procedimiento consultivo promovido por la Comisión Subregional de Pesca (CSRP) ante el TIDM (asunto núm. 21) ha contribuido a poner de manifiesto las dificultades que presenta una adecuada articulación de la participación de la UE y los Estados miembros en los procedimientos ante órganos judiciales internacionales. Asimismo, ha permitido al Tribunal de Justicia

1 Profesora titular de Derecho Internacional Público. Titular de la Cátedra Jean Monnet de Derecho de la Unión Europea. Universidad de Cantabria. 
clarificar ciertos aspectos relativos a la definición de la posición y representación de la Unión ante las cortes y tribunales internacionales.

\title{
Palabras clave
}

Representación exterior de la Unión Europea; equilibrio institucional; cortes y tribunales internacionales; CNUDM; TJUE; TIDM.

\section{THE EUROPEAN UNION AND THE MEMBER STATES PARTICIPATION IN JURISDICTIONAL PROCEDURES FOR THE SETTLEMENT OF DISPUTES UNDER UNCLOS}

\begin{abstract}
The European Union is increasing its participation in dispute settlement systems in the new framework of proliferation of international courts and tribunals. Specifically, the rules of the United Nations Convention on the Law of the Sea (UNCLO) on jurisdictional settlement of disputes provided in section 2 of Part XV contains express provisions dealing with the participation of EU which are of interest to the study of the issue. Furthermore, there has been decisive progress of the EU and the Member State's practice before the International Tribunal for the Law of the Sea (ITLOS). Recently, the advisory proceeding initiated by the Sub-regional Fisheries Commission (SRFC), before ITLOS (case num. 21) highlighted the internal difficulties involved in the appropriate coordination of the EU and the Member State's participation in proceedings before international tribunals. Additionally, the European Court of Justice has clarified a number of issues concerning the definition of EU position and its representation before international courts and tribunals.
\end{abstract}

\section{Keywords}

EU external representation; institutional balance; international courts and tribunals; UNCLOS; CJEU; ITLOS.

\section{L'UNION EUROPÉENNE ET LES ÉTATS MEMBRES DANS LES PROCÉDURES DE RÈGLEMENT JURIDICTIONNEL DES DIFFÉRENDS DE LA CNUDM}

\section{Résumé}

L'Union Européenne renforce sa participation dans les systèmes de règlement des différences dans le cadre de la prolifération de tribunaux internationaux. En particulier, le système de règlement juridictionnel des différends de la section 2 Part XV de la CNUDM comprend des dispositions particulières sur la participation de l'Union Européenne qui présentaient un grand intérêt pour l'examen de cette question. Plus 
précisément, se produit un développement progressif de la pratique de l'Union Européenne et les États Membres devant le Tribunal International du Droit de la Mer. Récemment, la participation de l'Union Européenne et les États Membres dans le procédure consultative devant le TIDM engagée par la Commission Sous Régionale des Pêches (CSRP) a permis de constater les difficultés que soulève une coordination adéquate de leur participation aux procédures devant les tribunaux internationaux. Par ailleurs, la Cour de Justice a contribué à clarifier des questions relatives à la définition de la position de l'Union Européenne et sa représentation devant les cours et tribunaux internationaux.

\section{Mots clés}

Représentation de l'Union Européenne; équilibre institutionnel; cours et tribunaux internationaux; CNUDM; CJUE; TIDM. 


\section{SUMARIO}

I. INTRODUCCIÓN. II. LA UNIÓN EUROPEA Y LOS ESTADOS MIEMBROS EN EL SISTEMA DE ARREGLO DE CONTROVERSIAS DE LA CNUDM: 1. Los procedimientos de arreglo jurisdiccional de la CNUDM; 2. Las previsiones expresas sobre la participación de la UE en los procedimientos de arreglo jurisdiccional de la CNUDM. III. LA PARTICIPACIÓN DE LA UNIÓN EUROPEA Y LOS ESTADOS MIEMBROS EN LOS PROCEDIMIENTOS ANTE EL TRIBUNAL INTERNACIONAL DE DERECHO DEL MAR: 1. La práctica de los Estados miembros ante el TIDM; 2. La práctica de la UE ante el TIDM: especial referencia al procedimiento consultivo promovido por la Comisión Subregional de Pesca (asunto núm. 21). IV. LA DEFINICIÓN DE LA POSICIÓN Y LA REPRESENTACIÓN DE LA UNIÓN EUROPEA ANTE LOS TRIBUNALES INTERNACIONALES. V. CONCLUSIONES.

\section{INTRODUCCIÓN}

La Unión Europea está incrementando su participación en los sistemas de arreglo de controversias en un contexto caracterizado por la proliferación de jurisdicciones internacionales ${ }^{2}$. La inclusión de cláusulas específicas sobre la

2 Hasta comienzos de los años noventa, la Unión Europea mantuvo una posición de contención en relación con el recurso a procedimientos internacionales de solución de controversias conducentes a decisiones obligatorias. Su práctica inicial en materia de arbitraje, calificada todavía en aquella etapa como errática, ha ido dando paso a una política más coherente en el recurso al arbitraje internacional y una mayor apertura en el recurso a otros medios, incluidos los tribunales internacionales. Allan ROSAS, "The European Union and International Dispute Settlement», en Lawrence BOISSON DE CHAZOURNES, Cesare, P. R. ROMANO y Ruth MACKENZIE (dirs.), International organisations and international dispute settlement: trends and prospects, Transnational Publisher, New York, 2002; «International Dispute Settlement — EU Practices and Procedures», German Yearbook of International Law, núm. 46, 2003, pp. 284-321; José Manuel SOBRINO HEREDIA, «Los procedimientos de solución de diferencias previstos en los acuerdos celebrados por la Comunidad Europea», en Hacia 
participación de organizaciones regionales de integración económica - REIO clauses -3 , organizaciones regionales de integración - RIO clauses $-{ }^{4}$ o específicamente la UE, en un número creciente de tratados multilaterales ha hecho posible su incorporación a los denominados regímenes jurídicos especiales en derecho internacional; principalmente, el sistema de la Organización Mundial del Comercio (OMC) y el sistema de la Convención de las Naciones Unidas sobre el Derecho del Mar (CNUDM), dotados de complejos sistemas de arreglo de controversias en los que se contempla el recurso a mecanismos de carácter jurisdiccional. Actualmente, pueden encontrarse tendencias similares, aunque con características particulares, en el marco de desarrollo de la competencia en materia de inversiones — art. 207 TFUE— 5 . Un caso particular y más complejo

un nuevo orden internacional y europeo. Estudios en homenaje al Profesor Don Manuel Diez de Velasco, Tecnos, Madrid, 1993, pp. 1221-1240; Peter Jan KUIJPER, «The European Communities and Arbitration", en Alfred H. A., SOONS, (ed.), International Arbitration: Pass and Prospects, Kluwer, The Hague, 1989, pp. 181-188.

El tratamiento de esta cuestión tiende actualmente a enmarcarse, al menos parcialmente, en el ámbito de la participación de la UE en instituciones y foros internacionales — art. 220 TFUE — En tal sentido, Edith DRIESKENS y Louise G. VAN SCHAIK, (eds.), The EU and Effective Multilateralism: Internal and External Reform Practices, Routledge, London/New York, 2014; Eric JØRGENSEN y Katie Verlin LAATIKAINEN, K.W. (eds.), Handbook on the European Union and International Institutions: Performance, Policy, Power, Routledge, London, 2013; Juan SANTOS VARA, «EU representation to International Organizations: A Challenging Task for the EEAS», en Luis N. González Alonso (ed.), Between autonomy and cooperation: shaping the institutional profile of the European External Action Service, CLEER 2014/6; Jamal SHAHIN (eds.), The Performance of the EU in International Institutions, Routledge, London/New York, 2013; Steven BLOCKMANS y Ramses A. WESSEL, "The Legal Framework for the Participation of the European Union in International Institutions", Journal of European Integration, núm 33, 2011, pp. 621-635; Ramses A. WESSEL, R.A. (eds.), Principles and Practices of EU External Representation, The Hague, CLEER Working Paper series, 2012.

Un estudio y sistematización de la práctica más reciente de la UE ante los tribunales internacionales en Frank HOFFMEISTER, «The European Union and the Peaceful Settlement of International Disputes», Chinese Journal of International Law, núm. 11 (1), 2012, pp. 77-105

3 Convenio de las Naciones Unidas sobre Diversidad Biológica, Río de Janeiro, 5 de junio de 1992.

4 Convención de las Naciones Unidas sobre los Derechos de las Personas con Discapacidad, Nueva York, 13 de diciembre de 2006.

5 Javier DÍEZ-HOCHLEITNER RODRÍGUEZ, «La protección de las inversiones en el TTIP: claves del debate», Revista General de Derecho Europeo, núm. 37, 2015; An- 
es el relativo a la adhesión de la Unión Europea al Convenio Europeo de Derechos Humanos - tal y como contempla el art. 6 (2) TUE-.

Los tratados de la Unión no han considerado de un modo expreso la cuestión de la facultad de la UE y los Estados miembros de asumir compromisos internacionales en materia de arreglo jurisdiccional de controversias. No obstante, esta cuestión tuvo un desarrollo muy temprano en la práctica de la Comunidad Económica Europea y la jurisprudencia del Tribunal de Justicia. Su posición al respecto se ha desarrollado, principalmente, en relación con el ejercicio de su competencia para pronunciarse mediante dictamen sobre la compatibilidad con los tratados de la Unión de cualquier acuerdo previsto, en virtud del art. 218 (11) TFUE ${ }^{6}$. Así, cabe recordar que ya en su Dictamen 1/91, de 14 de diciembre de 1991, el Tribunal de Justicia admitió que un acuerdo internacional puede tener por efecto la creación o designación de un mecanismo jurisdiccional diferenciado que vincule a la Unión ${ }^{7}$. Del mismo modo, el Tribunal de Justicia se ha pronunciado sobre los límites impuestos

gelos DIMOPOULOS, «The Compatibility of Future EU Investment Agreements with EU Law», Legal Issues of Economic Integration, núm. 39, pp. 447-471; Steffen HINDELANG, "The Autonomy of the European Legal Order - EU Constitutional Limits to Investor-State Arbitration on the Basis of Future EU Investment-related Agreements", European Yearbook of International Economic Law, 2013, pp 187-198; «Repellent Forces: The CJEU and Investor-State Dispute Settlement», Archiv des Völkerrechts, núm. 53, 2015, pp.68-79; Matthew PARISH, «International Courts and the European Legal Order", European Journal of International Law, vol. 23, núm. 1, 2012, pp. 141-153; Stephan W SCHILL, «Luxembourg Limits: Conditions for Investor-State Dispute Settlement under Future EU Investment Agreements», en Marc BUNGENBERG; August REINISCH y Chistrian TIETJE (eds.), EU and Investment Agreements: Open Questions and Remaining Challenges, Nomos/Hart Publishing Oxford, UK, 2013, pp. 37-54; "Opinion 2/13 - The End for Dispute Settlement in EU Trade and Investment Agreements?», The Journal of World Investment and Trade, vol. 16, 2015, pp. 379-388; Vincent TOMKIEWICZ, «L'Union Europeenne dans le pretoire international: Commerce et investissements", en L. DUBLIN y C. M. RUNAVOT (dir.), Le phénomène institutionnel international dans tous ses états; transformation, déformation ou reformation?, Pédone, Paris, 2014, pp. 195-213.

6 Con carácter general, José Manuel SOBRINO HEREDIA, «La aportación jurisprudencial de los dictámenes del Tribunal de Justicia de las Comunidades Europeas", AFDUDC, núm.11, 2007, pp. 925-939.

7 Dictamen 1/91, EU:C:1991:490, apdos. 39-40. Al respecto, Vassilios SKOURIS, «The ECJ and the EFTA Court under the EEA Agreement: A Paradigm for International Cooperation between Judicial Institutions», en Carl BAUDENBACHER, Per TRESSELT y Thorgeir ÖRLYGSSON, The EFTA Court: Ten Years On, Hart, Oxford, 2005, pp. 123-129. 
a esa facultad con el fin de preservar la autonomía del derecho de la Unión, interpretando que esta queda menoscabada cuando, en virtud de un acuerdo internacional, otra jurisdicción internacional es llamada a pronunciarse sobre las competencias de la UE y los Estados miembros en las materias regidas por las disposiciones de dicho acuerdo ${ }^{8}$; cuando la interpretación realizada por una jurisdicción internacional tengan por efecto imponer a la UE y a sus instituciones, en el ejercicio de sus competencias internas, una interpretación determinada de las normas de derecho de la Unión recogidas en dicho acuerdo'; o cuando, de otro modo, las competencias de la UE y de sus instituciones, tal como las conciben los tratados, puedan quedar desvirtuadas ${ }^{10}$. Posteriormente, se suscitaron objeciones de este tipo relativas a la creación de un tribunal europeo de patentes ${ }^{11}$. Más recientemente, en su Dictamen de 18 de diciembre de 2014, relativo al proyecto de acuerdo de adhesión de la Unión al Convenio Europeo de Derechos Humanos, el Tribunal de Justicia ha incidido de manera particular sobre cuestiones de esta naturaleza ${ }^{12}$. En este sentido, se

8 Dictamen $1 / 91$, ibid., apdo. 34 en relación con el 35 y 36.

9 Dictamen 1/92, EU:C:1992:189, apartados 17 y 36; Dictamen 1/00, EU:C:2002:231, apdo. 13.

10 Dictamen 1/00, EU:C:2002:231, apdo. 12. En el asunto de la fábrica de Mox se suscitaba tanto esta como la anterior de las objeciones, de manera que «[1]a Cour les traité indistinctement, en laissant entendre que, s'agissant des différends entre états membres, une interprétation divergente du traité constitue déjà une atteinte à l'autonomie de l'ordre juridique communautaire» (Yann KERBRAT y Philippe MADDALON, "Arrêt du 30 mai 2006 — grande chambre, aff. C-459/03—, Commission des Communautés européennes c. Irlande, Affaire de l'Usine MOX: la CJCE rejette l'arbitrage pour le règlement des différends entre Etats membres», Revue Trimestrielle de Droit Européen, vol. 43, núm. 1, 2007, pp. 154-182, p. 173).

11 Dictamen 1/09, EU:C:2011:123. El propio Tribunal de Justicia observaba que el caso del Tribunal de Justicia de Benelux es distinto, dado que este último es un órgano jurisdiccional común a varios Estados miembros, integrado en consecuencia en el sistema jurisdiccional de la Unión y sus resoluciones están sometidas a mecanismos que permiten asegurar la plena eficacia de las normas de la Unión (Sentencia de 4 de noviembre de 1997 Parfums Christian Dior, C-337/95, EU:C:1997:517). La alternativa ha sido la celebración del Acuerdo sobre un Tribunal Unificado de Patentes, de 19 de febrero de 2013, entre 25 Estados miembros de la Unión entre los que no se encuentra España. A 25 de enero de 2016, han ratificado el Acuerdo TUP los siguientes Estados: Portugal, Malta, Austria, Bélgica, Dinamarca, Francia, Luxemburgo, Suecia y Finlandia.

12 Piet EECKHOUT, «Human Rights and the Autonomy of EU Law: Pluralismo or Integration?», Current Legal Problem, vol. 66, núm. 1, 2013, pp. 173-174; Edouart DUBOUT, «Une question de confiance: nature juridique de l'Union Européene et 
ha criticado su posición de carácter proteccionista y «su concepción negativa de la autonomía del derecho de la Unión» ${ }^{13}$.

En este contexto, nuestro estudio se centra en la consideración de la posición de la Unión Europea en el sistema de arreglo de controversias de la CNUDM teniendo en cuenta la existencia de previsiones expresas sobre su participación, con características particulares, en los procedimientos de arreglo jurisdiccional previstos en la sección 2 de la parte XV. Dichas disposiciones establecen un principio de jurisdicción obligatoria con libre elección del foro reconociendo, a los Estados parte y a la Unión Europea como entidad parte, la facultad de opción entre distintos órganos arbitrales y judiciales. Aunque, en este contexto, se mantienen las restricciones que figuran en el Estatuto de la CIJ para la Unión Europea en tanto que organización internacional, se posibilita su acceso al Tribunal Internacional de Derecho del Mar (TIDM). De hecho, las previsiones sobre la participación de la Unión Europea han sido objeto de desarrollo en el Reglamento del TIDM, en tanto carecen de tal desarrollo cuando es otro el juez competente en virtud del art. 287 CNUDM $^{14}$.

En términos generales, tanto el funcionamiento del conjunto de las disposiciones de la sección 2 de la parte XV de la CNUDM como la actividad del TIDM presentan actualmente un carácter limitado ${ }^{15}$. Lo mismo sucede con la práctica desarrollada en este marco por la Unión Europea y los Estados miembros. No obstante, este desarrollo ha sido suficiente para que se susciten cuestiones jurídicas de gran interés teórico y práctico. Así, por ejemplo, en la

adhésion à la Convention européenne des droits de l'homme», Cahiers de droit européen, núm. 51, 2015; José MARTÍN Y PÉREZ DE NANCLARES, «La Unión Europea pierde el rumbo en el dictamen 2/13: merece todavía la pena la adhesión de la UE al CEDH», Revista de Derecho Comunitario Europeo, núm. 52, 2015, pp. 825-869.

13 Jet ODDERMAT, The Principle of Autonomy in EU External Relations, EUI Working Paper, MWP 2017/06. Una orientación distinta se encuentra en aquellos estudios que contribuyen a poner de manifiesto una aproximación más positiva del Tribunal de Justicia al diálogo judicial, particularmente en relación con los asuntos Brita y ATAA, en Eva KASSOTI, «Fragmentation and Inter-Judicial Dialogue: The CJEU and the ICJ at the Interface», European Journal of Legal Studies, vol. 8, núm. 2, 2015, pp. 21 49.

14 Tullio TREVES, «Union Européenne et règlement des différends dans le cadre de la Convention des Nations Unies sur le Droit de la Mer. Aspects Récents», Droit international de la mer et Droit de l'Union Européenne: Cohabitation, confrontation, coopération?, INDEMER, Colloque de Monaco, Pédone, París, 2014. pp. 339-346, p. 339.

15 Robin CHURCHILL, Compulsory' Dispute Settlement under the United Nations Convention on the Law of the Sea - How has it operated?, disponible en: http://www. jus.uio.no/pluricourts/english/blog/guests/2016-06-09-churchill-unclos-pt-1.html. 
controversia entre Irlanda y Reino Unido en el asunto de la fábrica de Mox, el Tribunal de Justicia fue llamado a interpretar, por primera vez en vía contenciosa, el alcance de su competencia exclusiva en virtud del actual art. 344 TFUE $^{16}$. En consecuencia, hubo de pronunciarse de manera específica sobre los límites del recurso a los procedimientos de arreglo jurisdiccional previstos en la CNUDM en las controversias entre Estados miembros, procediendo así a la interpretación del art. 344 TFUE en relación con el art. 282 CNUDM. No obstante, la posición adoptada por el Tribunal de Justicia en este caso presenta indudablemente un interés general al informar sobre los problemas de concurrencia de jurisdicciones, el marco de las relaciones entre el TJUE y otras jurisdicciones internacionales y la creciente importancia y complejidad del diálogo judicial en la sociedad internacional ${ }^{17}$.

Más recientemente, el primer procedimiento consultivo suscitado ante el pleno del TIDM (asunto núm. 21), ha contribuido a poner de manifiesto el interés político y jurídico que pueden llegar a presentar, para la Unión Europea y los Estados miembros, los procedimientos iniciados ante órganos judiciales internacionales en el marco del sistema de arreglo de controversias de la CNUDM. La opinión consultiva emitida por el pleno del TIDM el 2 de abril de 2015, aborda la relevante cuestión del contenido y alcance las obligaciones y responsabilidad de los Estados ribereños y Estados de pabellón, así como de las organizaciones internacionales competentes —en particular, la Unión Europea-, en relación con la pesca ilegal, no declarada y no regulada (INDNR) ${ }^{18}$. Dicho procedimiento ha contribuido significativamente a la reflexión sobre las dificultades que entraña una adecuada articulación de la participación de la UE y los Estados miembros en los procedimientos ante tribunales internacionales. Concretamente, en su Sentencia de 6 de octubre de 2005, el Tribunal de Justicia se ha pronunciado sobre la interpretación de ciertas disposiciones — principalmente, los arts. 218 (9) TFUE y 16 (1) TUE - y las exigencias derivadas del principio del equilibrio institucional y el deber de cooperación leal —art. 13 (2) TUE— en relación con las funciones de representación de la Unión Europea en un procedimiento judicial

16 Sentencia delTribunal de Justicia Comisión/Irlanda, C-459/03, ECLI:EU:C:2006:345.

17 En relación con la importancia del diálogo judicial europeo e internacional, Pierre-Marie DUPUY «Unité d'Application du Droit International à l'Echelle Globale et Responsabilité des Juges», European Journal of Legal Studies, 2007, núm 2; Allan ROSAS, "European Court of Justice in Context: Forms and Pattners of Judicial Dialogue», European Journal of Legal Studies, vol.1, núm. 2, 2007.

18 ITLOS, Advisory Opinion of 2 April 2015 (www.itlos.org/en/cases/list-of-cases/case$\left.\mathrm{n}^{\mathrm{o}}-21\right)$. 
internacional —art. 335 TFUE— ${ }^{19}$. De nuevo, aunque la cuestión se inscribe necesariamente en el marco de la CNUDM y su sistema de arreglo de controversias, las conclusiones que se derivan de este asunto presentan un interés general para el estudio de la definición de la posición y la representación de la Unión Europea ante los tribunales internacionales.

En este sentido, nos ocuparemos, en primer lugar, del marco jurídico general relativo a la participación de la Unión Europea y los Estados miembros en los procedimientos de arreglo jurisdiccional contemplados en la sección 2 de la parte XV de la CNUDM, tomando en consideración la existencia de previsiones expresas sobre la participación de la UE en dichos procedimientos. A continuación, consideraremos la práctica desarrollada por la Unión Europea y los Estados miembros ante el TIDM, incidiendo de manera especial en el tratamiento del procedimiento consultivo emprendido por la Subcomisión Regional Pesquera (asunto núm. 21). Finalmente, consideraremos las cuestiones relativas a la definición de la posición y representación de la Unión ante los tribunales internacionales, para terminar con unas breves conclusiones.

\section{LA UNIÓN EUROPEA Y LOS ESTADOS MIEMBROS EN EL SISTEMA DE ARREGLO DE CONTROVERSIAS DE LA CNUDM}

Desde la creación de la CEE, la UE ha desarrollado su Política Pesquera Común (PPC) —arts. 38 a 43 TFUE— ${ }^{20}$ y se ha dotado, más recientemente, de una Política Marítima Integrada (PMI ${ }^{21}$ y una Estrategia de Seguridad Marítima $(\mathrm{ESM})^{22}$. En la actualidad, cuenta con una intensa actividad de celebración de acuerdos con terceros Estados y otras organizaciones internacionales en materias como la pesca, la contaminación del medio marino o el trabajo marítimo. Como ejemplifican, asimismo, la acción emprendida por la Unión Europea en la lucha contra la piratería a través de la operación ATALANTA y su contribución a la promoción de un acuerdo internacional sobre

19 Sentencia del Tribunal de Justicia Consejo/Comisión, C-73/14, EU:C:2015:663.

20 José Manuel SOBRINO HEREDIA (coord.), «Número monográfico: Política Pesquera Común», Noticias de la Unión Europea, núm. 326, 2012.

21 Comisión Europea, Comunicación sobre una política marítima integrada para la Unión Europea, de 10 de octubre de 2007, COM (2007) 575 final. En 2011 se adoptó el Reglamento 1255/2011, del Parlamento Europeo y del Consejo, de 30 de noviembre de 2011, por el que se establece un Programa de Apoyo para la Consolidación de la Política Marítima integrada, DO L 321, de 5 de diciembre de 2011, pp. 1-10.

22 Consejo de la Unión Europea, Estrategia de Seguridad Marítima de la Unión Europea, Doc. 11205/14, 24 de junio de 2014. 
la biodiversidad marina en las zonas fuera de la jurisdicción nacional, todas sus iniciativas internas e internacionales en la materia se encuentran ampliamente influenciadas por la CNUDM y sus acuerdos complementarios ${ }^{23}$.

La denominada "Cláusula CEE» — esto es, el art. 1 (2) (2) de la Convención, en conexión con su art. 305 (1) (f) y el art. 1 del Anexo IX- dispone que la CNUDM se aplique mutatis mutandis a las organizaciones intergubernamentales constituidas por Estados que les hayan transferido competencias en materias regidas por la misma, incluida la de celebrar tratados en relación con ellas ${ }^{24}$. En aplicación de estas disposiciones, la CNUDM fue ratificada tanto por los Estados miembros como por la Comunidad Europea, siendo así considerada como el primer tratado multilateral de carácter general perteneciente a la categoría de los acuerdos mixtos ${ }^{25}$. La CE realizó entonces la

23 Román LONG, «The European Union and Law of the Sea Convention at the Age of 30», The International Journal of Marine and Coastal Law, núm. 27, 2012, pp. 711-721. Un estudio de la jurisprudencia más reciente del Tribunal de Justicia en el sector del derecho del mar en Gabriela A. OANTA, «Tres sentencias claves para la delimitación del contorno jurídico de las competencias convencionales de la Unión en el ámbito pesquero", Revista de Derecho Comunitario Europeo, núm. 53, 2016, pp. 201-231.

24 Sobre la participación de la CEE en el proceso de negociación en calidad de observador, Myron H. NORDQUIST, et al., United Nations Convention on the Law of the Sea 1982: A Commentary, vol. 1, p. 84; Albert W. KOERS, «Participation of the European Economic Community in a New Law of the Sea Convention", AJIL, núm. 73, 1979, pp. 426-441; Fried WEISS, "UNCLOS and the EEC: Some Legal Problems», en Willian E. BUTLER (ed.), The Law of the Sea and International Shipping: Anglo-Soviet post-UNCLOS Perspectives, Oceana Publications, New York, 1985, pp. 69-103; Daniel VIGNES, "The EEC and the Law of the Sea», en H. LAY, R. CHURCHILL, Myron H. NORDQUIST, Kenneth SIMMONDS y Jane WELCH (eds.), New Directions in the Law of the Sea, 1973, pp. 335-347.

25 Decisión 98/392/CE del Consejo, de 23 de marzo de 1998, relativa a la celebración por la Comunidad Europea de la Convención de las Naciones Unidas sobre el Derecho del Mar de 10 de diciembre de 1982 y del Acuerdo de 28 de julio de 1994 relativo a la aplicación de la parte XI de dicha Convención (DO L 179 23.6.1998, p. 1). Al respecto, Dermott J. DEVINE, «Le caractère indivisible de la convention sur le droit de la mer et les implications de la signature pour la Communauté Economique Européenne et ses Etats Membres», RDMC, núm. 304, 1987, pp. 95-100; José JUSTE RUIZ, "La solución de controversias en el Convenio de las Naciones Unidas sobre el Derecho del Mar», en Valentín Enrique BOU (coord.), Nuevas controversias internacionales y nuevos mecanismos de solución, Valencia, Tirant lo Blanch, 2005; LONG, op. cit., nota 23, p. 713; "The inexorable Rise of the United Nations Convention on the Law of the Sea within the European Legal Order», en Peaceful Order in the 
declaración sobre el alcance de sus competencias en materia de derecho del mar prevista en el art. 5 (1) del anexo IX y sobre la pesca en zonas situadas más allá de la ZEE ${ }^{26}$. En su condición de entidad parte en la CNUDM, la UE

World's Oceans, 2014, pp. 157-185; Christoph NORDMANN, «Regional Organisations: The European Community and the Law of the Sea Convention», en Davor VIDAS, y Willy ØSTRENG (eds.), Order for the Oceans at the Turn of the Century, The Hague: Kluwer, 1999, pp. 355-363; Esa PAASIVIRTA, "The European Union and the United Nations Convention on the Law of the Sea», Fordham International Law Journal, núm. 38, 2015, pp. 145-1071; Kenneth SIMMONDS, «The European Economic Community and the New Law of the Sea», Recueil des Cours de l'Académie de Droit International, vol. 6, núm. 218, 1989, pp. 9-166; "The Community's Participation in the U.N. Law of the Sea Convention», en David O'KEEFE y Henry G. SCHERMERS (eds.), Essays in European Law and Integration, 1982, pp. 79-191; José Manuel SOBRINO HEREDIA (coord.), The contribution of the United Nations Convention on the Law of the Sea to good governance of the oceans and seas / La contribution de la Convention des Nations Unies sur le droit de la mer à la bonne gouvernance des mers et océans / La contribución de la Convención de las Naciones Unidas sobre el Derecho del Mar a la buena gobernanza de los mares y océanos, Scientifica, Napoli, 2014; Tullio TREVES y L. PINESCHI (eds.), The Law of the Sea. The European Union and Its Member States, 1997; Tullio TREVES, «The European Community and the European Union and the Law of the Sea: Recent Developments», Indian Journal of International Law, núm. 48, 2008, pp. 1-20; Eva M. VÁZQUEZ GÓMEZ, María Dolores ADAM MUÑOZ y Noé CORNAGO PRIETO (coords.), El arreglo pacífico de controversias internacionales, Tirant lo Blanch, Valencia, 2013.

26 Atendiendo a la evolución en el sistema de distribución de competencias, la Comunidad se reservó entonces la facultad de modificar su declaración — tal y como ha previsto el art. 5 (4) del anexo IX - aunque nunca lo ha hecho. Está situación puede generar dificultades prácticas, si bien los arts. 5 (5) y 6 (2) del mismo anexo facultan a los Estados parte para pedir a una organización internacional y a sus Estados miembros que también sean partes que informen acerca de quién tiene competencia respecto de una cuestión concreta que haya surgido y a quién incumbe la responsabilidad respecto de una determinada cuestión, respectivamente. La organización y los Estados miembros de que se trate comunicarán esa información en un plazo razonable. Podrán comunicar esa información por iniciativa propia. El hecho de no dar esa información en un plazo razonable o de dar información contradictoria entrañará responsabilidad conjunta y solidaria. Al respecto, Kenneth SIMMONDS, K., "The Community's Declaration upon Signature of the UN Convention on the Law of the Sea», CML Rev. núm. 23, 1986, pp. 521-544; Liesbeth LIJNZAAD, «Declarations of competence, a very European Affair», en Michael W. LODGE y Myron H. NORDQUIST (eds.), Peaceful Order in the World's Oceans: Essays in Honor of Satya N. Nandan, Martinus Nijhoff, 2014, pp. 186 y ss.; Advisory Report on European External Action and Inter- 
participa en los foros competentes para el desarrollo progresivo del derecho del mar; en particular, las Reuniones de Estados parte y la Asamblea General de las Naciones Unidas; participación que ha tendido a reforzarse, con carácter general, en los últimos años ${ }^{27}$.

La Unión Europea es, asimismo, parte en el Acuerdo de 28 de julio de 1994 relativo a la aplicación de la parte XI de la CNUDM y en el Acuerdo sobre la Aplicación de las Disposiciones Relativas a la Conservación y Ordenación de las Poblaciones de Peces Transzonales y las Poblaciones de Peces Altamente Migratorios, en el que asumió un papel destacado como negociador ${ }^{28}$. De hecho, en la actualidad, la Unión es parte en un amplio número de tratados multilaterales, regionales y bilaterales en materia de gestión y conservación de recursos pesqueros. Asimismo, ha ido incrementando progresivamente su presencia en las organizaciones internacionales regionales competentes en materia de pesquerías ${ }^{29}$.

national Law, Advisory Committee on Issues of Public International Law (CAVV), Advisory Report núm. 24, The Hague, May 2014.

27 Tullio TREVES, «The General Assembly and the Meeting of the States Parties in the Implementation of the LOS Convention, en Alex G. OUDE (ed.), Stability and Change in the Law of the Sea: The Role of the LOS Convention, Nijhoff, 2005.

28 Decisión 98/414/CE del Consejo, de 8 de junio de 1998, relativa a la ratificación, por parte de la Comunidad Europea, del Acuerdo sobre la Aplicación de las Disposiciones de la Convención de las Naciones Unidas sobre el Derecho del Mar, de 10 de diciembre de 1982, relativas a la conservación y ordenación de las poblaciones de peces transzonales y las poblaciones de peces altamente migratorios (DO L 189 de 3.7.1998, p. 14). NORDMANN, op. cit., nota 25, pp. 355-363.

29 La UE, representada por la Comisión, ejerce un papel activo en seis organizaciones atuneras: Comisión Internacional para la Conservación del Atún Atlántico (CICAA); Comisión del Atún para el Océano Índico (CAOI); Comisión de Pesca del Pacífico Occidental y Central; Comisión Interamericana del Atún Tropical (CIAT); Acuerdo sobre el Programa Internacional para la Conservación de los Delfines (APICD); Comisión para la Conservación del Atún del Sur; y 11 organizaciones de otro tipo: Comisión de Pesca del Atlántico Nordeste (CPANE); Organización de la Pesca del Atlántico Noroccidental (NAFO); Organización para la Conservación del Salmón del Atlántico Norte (OCSAN); Organización de la Pesca del Atlántico Suroriental (SEAFO); Acuerdo de Pesca para el Océano Índico Meridional (SIOFA); Organización Regional de Ordenación Pesquera del Pacífico Sur; Convenio para la Conservación de los Recursos Vivos Marinos Antárticos (CCRVMA); Comisión General de Pesca para el Mediterráneo (CGPM); Convención sobre la Conservación y Ordenación de las Poblaciones de Abadejo en la Región Central del Mar de Bering. Dos de ellas son de carácter puramente consultivo: Comisión de Pesca del Atlántico Centro Occidental (COPACO); Comité de Pesca del Atlántico Centro Oriental (CPACO). Comunica- 


\section{LOS PROCEDIMIENTOS DE ARREGLO JURISDICCIONAL DE LA CNUDM}

El sistema de arreglo de controversias de la CNUDM está integrado por las disposiciones de la parte XI —aplicables a la solución de controversias relativas a la Zona Internacional de los Fondos Marinos y Oceánicos- y las disposiciones de la parte XV que se aplican con carácter general a las controversias relativas a la interpretación y aplicación de la CNUDM. La disposición básica de la parte XV es el art. 286 en el que se reafirma la obligación de los Estados parte - y la Unión Europea como entidad parte en virtud del art. 1 (2) (2) - de resolver las controversias relativas a la interpretación o aplicación de sus disposiciones por medios pacíficos, de conformidad con los arts. 2 (3) y 33 (1) de la Carta de las Naciones Unidas. En caso de que la controversia no pueda ser resuelta por los medios políticos elegidos por las partes, se contempla el recurso a los procedimientos obligatorios conducentes a decisiones obligatorias contemplados en la sección 2 de la parte XV. En concreto, a petición de cualquiera de las partes en la controversia, esta podrá ser sometida a los procedimientos de arreglo jurisdiccional previstos a tal efecto. No obstante, deben tenerse en cuenta las limitaciones y excepciones facultativas que figuran en la sección 3 de la Parte XV —en particular, los arts. 297 y 298- para determinados tipos de controversias.

El art. 287 incorpora la denominada fórmula de Montreaux estableciendo que, al firmar o ratificar la CNUDM o al adherirse a ella, o en cualquier momento ulterior, los Estados podrán elegir libremente, mediante una declaración escrita, uno o varios de los medios siguientes para la solución de las controversias relativas a la interpretación o la aplicación de la Convención: a) el TIDM, constituido de conformidad con el Anexo VI; b) la Corte Internacional de Justicia; c) un tribunal arbitral constituido de conformidad con el anexo VII, y d) un tribunal arbitral especial, constituido de conformidad con el anexo VIII, para una o varias de las categorías de controversias que en él se especifican. En ausencia de declaración o en caso de que las partes no hayan aceptado el mismo mecanismo, se entenderá que es aplicable residualmente el procedimiento arbitral de conformidad con el anexo VII de la Convención.

Se ha previsto la extensión de la aplicación de este sistema a los acuerdos relativos a los propósitos de la $\mathrm{CNUDM}^{30}$, como ha quedado establecido en

ción de la Comisión al Consejo y al Parlamento Europeo sobre la participación de la Comunidad Europea en las Organizaciones Regionales de Pesca (ORP) Bruselas, $\mathrm{COM} / 1999 / 613$.

30 Art. 288 (1) (2) CNUDM. En la actualidad, existen en torno a 15 acuerdos internacionales de este tipo, si bien algunos de ellos aún no han entrado en vigor y ningún 
el Acuerdo sobre las Poblaciones de Peces Transzonales y las Poblaciones de Peces Altamente Migratorios, que remite en su art. 30 a la aplicación mutatis mutandi de las disposiciones de la parte XV de la CNUDM. Asimismo, su art. 30 (2) contempla una potencial extensión de dichas disposiciones a las controversias entre los Estados parte relativas a la interpretación y aplicación de acuerdos subregionales, regionales y globales sobre poblaciones de peces transzonales y poblaciones de peces altamente migratorios; esto es, a un significativo número de tratados sobre pesquerías.

Actualmente, son 167 los Estados parte en la CNUDM, además de la UE. De ellos, 45 Estados han hecho la declaración facultativa del art. $287^{31}$. Pueden hacerlo eligiendo una de las jurisdicciones contempladas, más de una o todas y estableciendo o no un orden de preferencia entre ellas. Concretamente, 19 de los 28 Estados miembros de la UE han realizado dicha declaración, de los cuales siete han formulado también la declaración prevista en el art. 298 excluyendo determinados tipos de controversias ${ }^{32}$.

La opción por la Corte Internacional de Justicia y el TIDM se encuentra bastante equilibrada, tanto en términos generales como en el caso de los Estados miembros de la UE. En efecto, 33 Estados han elegido el TIDM como primera opción ${ }^{33}$, en tanto que 20 Estados han elegido como primera opción la CIJ, si bien 13 de ellos elijen en el mismo plano al TIDM. Por razones políticas, Cuba y Guinea Bissau han declarado expresamente que rechazan la competencia de la CIJ.

asunto ha sido sometido aún por esta vía a los procedimientos jurisdiccionales de la sección 2 de las partes XV de la CNUDM.

31 En virtud de la Declaración de 15 de enero de 1997, España atribuyó competencia únicamente a la CIJ, pero la amplió posteriormente al TIDM y a la CIJ en virtud de una declaración con efectos a partir del 19 de julio de 2002. Además, declara que, de conformidad con lo dispuesto en el párrafo 1.a) del art. 298 de la Convención, no acepta los procedimientos previstos en la Sección 2 de la parte XV para la solución de las controversias relativas a la interpretación o la aplicación de los arts. 15, 74 y 83 concernientes a la delimitación de las zonas marítimas, o las relativas a bahías o títulos históricos (BOE núm. 170, 17 de julio de 2003, p. 27843). Por aplicación de dicha competencia contenciosa, España fue demandada ante el TIDM por San Vicente y Las Granadinas en noviembre de 2010 en el asunto $M / V$ "Louisa», concluido con una sentencia de 28 de mayo de 2013.

32 Dinamarca, Francia, Italia, Portugal, Eslovenia, España y Reino Unido.

33 Además, tres Estados — la Federación Rusa, Bielorrusia y Ucrania - lo han elegido como primera opción, pero simplemente en relación con el procedimiento de pronta liberación de buques y sus tripulaciones 
Por su parte, la mayoría de los Estados miembros de la Unión eligen la CIJ y el TIDM en pie de igualdad como primera opción ${ }^{34}$. A su vez, cinco Estados han aceptado la competencia del TIDM como primera opción excluyendo el recurso a la $\mathrm{CIJ}^{35}$ y cuatro eligen como primera opción la CIJ excluyendo el recurso al TIDM ${ }^{36}$. Eslovenia designa como única elección el procedimiento arbitral del Anexo VII.

En términos generales, se constata que el interés mostrado por los Estados en relación con estas disposiciones ha ido en aumento, pero es todavía limitado. El resultado es, en cualquier caso, una prevalencia del recurso al arbitraje del anexo VII. Puede pensarse que, siendo esta la opción residual, la preferencia de los Estados por el arbitraje desincentiva la realización de declaraciones facultativas. No obstante, no parece ser así si se tiene en cuenta que, un número significativo de asuntos contenciosos iniciados ante el TIDM - concretamente, 5 asuntos—, le fueron sometidos por acuerdo entre las partes tras haberse instado inicialmente el procedimiento residual de arbitraje. Ningún asunto ha sido sometido a la CIJ ni el Tribunal Arbitral del anexo III en virtud de las disposiciones de la sección 2 de la Parte XV de la CNUDM. En cualquier caso, la CIJ ha conocido de diversos asuntos en materia de derecho del mar —en gran medida relativos a la delimitación de fronteras marítimas- sobre otras bases jurídicas ${ }^{37}$.

34 Bélgica, Estonia, Finlandia, Italia, Letonia, Lituania y España. Portugal es el único Estado que elige en igualdad los cuatro órganos jurisdiccionales previstos.

35 Austria, Croacia, Alemania, Hungría y Grecia.

36 Reino Unido, Dinamarca, Holanda y Suecia.

37 JIMÉNEZ PIERNAS, C., «La jurisprudencia sobre delimitación de los espacios marinos: una prueba de la unidad del ordenamiento internacional», en VÁZQUEZ GÓMEZ, ADAM MUNOOZ y CORNAGO PRIETO, op. cit., nota 25, pp. 241 276.

Por otro lado, un caso que ejemplifica la opción por el recurso al arbitraje fuera del marco de los procedimientos de arreglo jurisdiccional de la sección 2 de la parte XV de la CNUDM entre dos Estados miembros de la UE, es la disputa fronteriza entre Croacia y Eslovenia. No obstante, fue ya en 2009 cuando dichos Estados iniciaron un procedimiento arbitral en virtud de un acuerdo especial (The arbitration Agreement between the Government of the Republic of Slovenia and the Government of the Republic of Croatia, 4 November 2009, available at: http:// www.vlada.si/fileadmin/ dokumenti/si/projekti/2010/Arbitrazni_sporazum/10.a_Arbitra\%C5\%BEni_sporazum_-_podpisan_EN.pdf.). 


\section{LAS PREVISIONES RELATIVAS A LA PARTICIPACIÓN DE LA UNIÓN EUROPEA EN LOS PROCEDIMIENTOS DE ARREGLO JURISDICCIONAL DE LA CNUDM}

El art. 7 (2) del anexo IX de la CNUDM considera expresamente la aplicación, mutatis mutandis, de las disposiciones de la parte XV a las controversias entre partes en la CNUDM cuando una o varias sean organizaciones internacionales. Sin embargo, la UE no ha hecho uso de la facultad prevista en el art. 7, apdo. 1, del anexo IX en relación con el art. $287(1)^{38}$. La CIJ no es una opción real para la Unión ya que su Estatuto no reconoce ius standi a las organizaciones internacionales en los procedimientos contenciosos ${ }^{39}$, como se puso de manifiesto en el Asunto de la Jurisdicción en Materia de Pesquerías (España v. Canadá). Por tanto, las opciones abiertas para la Unión se limitan al TIDM y el arreglo arbitral.

En tanto la Unión Europea no realice su declaración escrita sobre libre elección del foro, se deduce del conjunto de estas disposiciones que en el caso de una demanda dirigida exclusivamente contra la Unión es aplicable residualmente el procedimiento arbitral previsto en el anexo VII de la CNUDM. Más complejo es el caso de que la Unión Europea y uno o varios de sus Estados miembros sean partes conjuntas en una controversia, o partes con un mismo interés. En tales supuestos, la pertenencia a la Unión puede tener un impacto en la facultad de los Estados de elegir foro, al producirse en ciertos casos la necesidad de una alteración

38 Desde un principio, la Comunidad Europea dejó abierta esta cuestión, pues manifestó que se abstenía de elegir un procedimiento específico de solución de controversias tal como se prevé en el art. 287 de la CNUDM y esa decisión se estudiaría en un plazo determinado. Decisión 98/392/CE del Consejo, cit.

39 Este hecho es considerado en el marco del art. 7 (1) del anexo IX de la Convención, que excluye esta opción al considerar las declaraciones de las organizaciones internacionales parte en virtud del art. 287 (1).

En términos generales, el reconocimiento a las organizaciones internacionales de ius standi en los procedimientos contenciosos es limitado, si bien han adquirido un cierto locus standi que les permite intervenir presentando alegaciones escritas y orales - art. 34 (2) (3) del Estatuto de la CIJ; art. 20 del Estatuto y 57 (2) del Reglamento del TIDM; art. 36 (2) (3) del Convenio Europeo de Derechos Humanos y art. 44 (3) (4) del Reglamento de Tribunal Europeo de Derechos Humanos- y actuar como amicus curiae (al respecto, Ruth MACKENZIE y Christine CHINKIN, «Intergovernmental Organizations as «Friends of the Court», en International organisations and international dispute settlement..., op. cit., nota 2, pp. 135 y ss.). Consecuentemente, también la Unión Europea ha ido desarrollando su práctica en relación con estas modalidades de participación. Un estudio de esta práctica reciente en HOFFMEISTER, op cit., nota 2. 
de su elección, prevista en la propia CNUDM. Así, en el caso de una participación conjunta de la Unión y los Estados miembros, según dispone el art. 7 (3) del anexo IX, «se considerará que la organización ha aceptado los mismos procedimientos de solución de controversias que los Estados miembros». Esta disposición es insuficiente en la eventualidad de que los Estados miembros en cuestión hayan hecho elecciones de foro diferentes, como probablemente sucedería. En tales casos, y a falta de acuerdo, la solución sería el recurso residual al arbitraje previsto en el anexo VII. Adicionalmente — como dispone expresamente el 7 (3)—, en los supuestos de participación conjunta de la Unión y Estados miembros, cuando los Estados miembros en cuestión hubieran elegido únicamente el recurso a la CIJ, se impone el recurso al arbitraje residual del anexo VII, salvo que las partes en la controversia acuerden otra cosa. Este es actualmente el caso de Reino Unido y Holanda, que únicamente eligen la CIJ.

En la práctica, el procedimiento arbitral residual del anexo VII ha sido activado en dos ocasiones para la Unión Europea - el asunto del Pez Espada (Chile v. Comunidad Europea) ${ }^{40}$ y la controversia entre la Unión Europea y Dinamarca, actuando en representación de las Islas Feroe, en el asunto Unión Europea-Medidas relativas al arenque atlántico-escandinavo ${ }^{41}$ - si bien en el primer caso las partes acordaron someter la controversia a una sala ad hoc del TIDM ${ }^{42}$. En ambos asuntos, se suscitaban controversias híbridas o complejas sometidas paralelamente a los procedimientos de solución de controversias de la CNUDM y de la OMC. Ambos casos concluyeron mediante acuerdos negociados por las partes.

\section{LA PARTICIPACIÓN DE LA UNIÓN EUROPEA Y LOS ESTADOS MIEMBROS EN LOS PROCEDIMIENTOS ANTE EL TRIBUNAL INTERNACIONAL DE DERECHO DEL MAR}

Aunque la actividad del TIDM desde su puesta en funcionamiento es limitada, ha ido experimentado un progresivo incremento. Fue inaugurado

40 Conservation and Sustainable Exploitation of Swordfish Stocks in the South-Eastern Pacific Ocean (Chile v. European Community), case num. 7, ITLOS (2000). Removed from docket 17 December 2009. Al respecto, Ted L. McDORMAN, 'The Chile v. EC Swordfish Case', Yearbook of International Environmental Law, núm. 11, 2000, 585 y ss.; Marcos ORELLANA, "The Swordfish Dispute between the EU and Chile at the ITLOS and the WTO', NJIL, núm. 71, 2002, pp. 55-81; Peter-Tobias STOLL y Silja VÖNECKY, «The Swordfish Case: Law of the Sea v. Trade», Zä̈RV, núm. 61, 2002, pp. 21-35.

41 Atlanto-Scandian Herring (Den. In respecto of Faroe Is. V. E.U.) P. C. A. Case 201330 .

42 International Tribunal for the Law of the Sea, Order 20 December 2000. 
formalmente el 18 de octubre de 1996, recibiendo su primer caso —el asunto Saiga - aproximadamente un año después. Hasta el momento, el Tribunal ha registrado 23 asuntos contenciosos, si bien la mayoría de ellos se inscriben en el marco de las competencias obligatorias de carácter residual que le atribuye la CNUDM; esto es, el procedimiento de pronta liberación de buques y sus tripulaciones del art. 292, y el procedimiento de medidas provisionales del art. 290 (5). Han sido nueve los asuntos registrados sobre pronta liberación de buques y sus tripulaciones, lo que ha dado lugar al desarrollo de una importante jurisprudencia en la materia. En cuanto a los procedimientos de medidas provisionales, el TIDM ha dictado nueve autos en el marco de sus competencias, tanto en virtud del art. 290 (1) como en virtud del art. 290 (5). En este contexto, las cuestiones relativas a la determinación de la jurisdicción prima facie y la noción de urgencia, son las que han suscitado mayores críticas.

\section{LA PRÁCTICA DE LOS ESTADOS MIEMBROS ANTE EL TIDM}

Por el momento, el TIDM ha conocido de dos procedimientos contenciosos dirigidos contra Estados miembros de la UE sobre la base de las declaraciones facultativas realizadas por los Estados parte en la controversia en virtud del art. 287 CNUDM. Se trata del asunto $M / V$ Louisa (San Vicente $y$ las Granadinas v. España ${ }^{43}$ y el asunto $M / V$ Norstar (Pánama v. Italia), este último actualmente en curso.

En el marco del procedimiento especial autónomo de pronta liberación de buques y sus tripulaciones se han sustanciado tres demandas contra un Estado miembro - asunto Camouco (Panamá v. Francia), asunto del Monte Confurco (Seychelles v. Francia) y asunto del Grand Pince (Belice v. Francia)—. En este sentido, conviene recordar que la propia declaración de competencias realizada en su momento por la CE precisa que, aunque la Unión Europea tiene competencia exclusiva en materia de conservación y gestión de recursos pesqueros, las medidas relativas al ejercicio de jurisdicción sobre los buques, el abanderamiento y registro de buques y la imposición de sanciones penales y

43 En relación con este asunto, Concepción ESCOBAR HERNÁNDEZ, «España y el TIDM: especial referencia al caso $M / V$ Louisa, en José MARTÍN Y PÉREZ DE NANCLARES (dir.), España y la práctica del Derecho Internacional, LXXV Aniversario de la Asesoría Jurídica Internacional del MEC, Colección Escuela Diplomática 20, Madrid, 2013, pp. 179-221; Mariano J. AZNAR GÓMEZ, «El Tribunal Internacional del Derecho del Mar», en VÁZQUEZ GÓMEZ, ADAM MUÑOZ y CORNAGO PRIETO (coords.), op. cit., nota 24, pp. 371-412; Rosario OJINAGA RUIZ, «The M/V «Louisa» Case: Spain and the International Tribunal for the Law of the Sea", Spanish Yearbook of International Law, núm. 18, pp.199-221 
administrativas son de competencia de los Estados miembros, aunque respetando las normas del derecho de la Unión. La propia UE contempla también sanciones administrativas ${ }^{44}$. Como observa el juez Treves, ello tiene incidencia en los procedimientos de pronta liberación de buques por su conexión con las funciones de policía y las sanciones contempladas en el art. 73 (2) CNUDM ${ }^{45}$. En el mismo sentido, es destacable el hecho de que varios Estados miembros hayan hecho las declaraciones previstas en el art. 298 (1) (b) CNUDM excluyendo del recurso a la jurisdicción obligatoria las controversias relativas a actividades encaminadas a hacer cumplir las normas legales respecto del ejercicio de los derechos soberanos en materia de pesca, lo que igualmente podría hacer la Unión Europea en relación con las medidas de control sobre los buques con pabellón de terceros Estados en las aguas de la Unión.

Finalmente, cuatro de los ocho autos de medidas provisionales dictados por el TIDM han recaído en asuntos en los que ambas partes eran Estados miembros de la Unión —asunto de la fábrica de Mox (Irlanda v. Reino Unido) — o lo era una de ellas —asunto M/V Louisa (San Vicente y las Granadinas v. España), asunto del Artic Sunrise (Dinamarca c. Federación Rusa) y asunto del incidente Enrika Lexie (India v. Italia)-.

Destacan, en este contexto, las implicaciones derivadas del asunto de la fábrica de Mox en relación con la competencia exclusiva atribuida al Tribunal de Justicia para conocer de las controversias marítimas entre Estados miembros en virtud del art. 344 TFUE y con el fin de preservar la autonomía del Derecho de la Unión ${ }^{46}$. De acuerdo con el art. 216 (2) TFUE y la jurisprudencia del Tribunal

44 También debe tenerse en cuenta la previsión expresa que figura en la Declaración de competencias, sobre su no aplicación a los territorios de los Estados miembros en que los tratados de la Unión no son aplicables y sin perjuicio de las medidas o posiciones que puedan adoptar los Estados miembros de que se trate.

46 Vicenta CARREÑO GUALDE, «TJCE - Sentencia de 30.05.2006, Comisión/Irlanda, C-459/03, MOX — La competencia exclusiva del TJCE y la Parte XII de la Convención de las Naciones Unidas sobre el Derecho del Mar», Revista de Derecho Comunitario Europeo, núm. 26, 2007, pp. 185-202; Julien CAZALA, «La contestation de la compétence exclusive de la Cour de justice des Communautés européennes. Étude des relations entre divers systèmes internationaux de règlement des différends", Revue Trimestrielle de Droit Européen, vol. 40, núm. 3, 2004, pp. 505-553; Yann KERBRAT, «Le différend relative à l'usine Mox de Sellafield (Irlande/Royaume-Uni): connexité des procedures et droit d'accès à l'information en matière environnementale", Annuaire Francaise de Droit International, 2006, pp. 607623; KERBRAT y MADDALON, op. cit., nota 10; Javier LASO PÉREZ, «La jurisdicción obligatoria del TJCE y los medios de solución de controversias en los acuerdos mixtos. Comentario a la Sentencia del TJCE de 30 de mayo de 2006, C-459/03, Comisión c. Irlanda», RGDE, núm. 11, 2006, pp.12-13; Nicolaos LAVRANOS, «The MOX Plant judgment 
de Justicia ${ }^{47}$, los acuerdos celebrados por la UE y los acuerdos mixtos forman parte del ordenamiento jurídico de la Unión ${ }^{48}$. Asimismo, en ejercicio de su competencia para interpretar los acuerdos celebrados por la Unión, incumbe al Tribunal de Justicia garantizar su aplicación uniforme en esta ${ }^{49}$. En tal sentido, en su sentencia de 30 de mayo de 2006, el Tribunal de Justicia sostuvo que «[...] un convenio internacional como la Convención no puede menoscabar la competencia exclusiva del Tribunal de Justicia en lo que atañe a la solución de controversias entre Estados miembros relativas a la interpretación y a la aplicación del Derecho comunitario. Además [...] el art. 282 de la Convención permite precisamente garantizar que no se produzca tal menoscabo y, por lo tanto, que quede efectivamente salvaguardada la autonomía del sistema jurídico comunitario" " ${ }^{50}$.En tal sentido, el Tribunal de Justicia procede en dicha sentencia a una interpretación expansiva de su monopolio jurisdiccional en virtud del art. 344 TFUE — antiguos arts. 292 TCE y 193 TEA-.

of the ECJ: How exclusive is the jurisdiction of the ECJ?», European Environmental Law Review, 2006, núm. 15, pp. 291-296; «The MOX Plant and Ijzeren Rijn Disputes; Which Court is the Supreme Arbitrer?», Leiden Journal of International Law, núm. 19, 2006, pp. 223-246; Sandrine MALJEAN-DUBOIS y Jean-Chirstophe. MARTÍN (2007): «Laffaire de l'Usine Mox devant les tribunaux internationaux", Journal de Droit International, núm. 2, 2007, pp. 437-471; Rosario OJINAGA RUIZ, «La competencia exclusiva del TJCE en las controversias entre Estados miembros relativas a la aplicación del Derecho Comunitario y el recurso a los procedimientos jurisdiccionales internacionales de arreglo de controversias. El asunto de la fábrica de MOX» en Consuelo ARRANZ DE ANDRÉS y Margarita SERNA VALLEJO, (coord.), Estudios de Derecho Español y Europeo: libro conmemorativo de los primeros 25 años de la Facultad de Derecho de la Universidad de Cantabria, 2009, pp. 677-706. Tribunal de Justicia Intertanko y otros, C-308/06, EU:C:2008:312. Las críticas doctrinales en Robin CHURCHILL y Daniel OWEN, The EU Common Fisheries Policy, 2010, pp. 315-316; Eileen DENZA, "A note on Intertanko», EJIL, núm. 33, 2008, pp. 870-879; J, GIRARD, «Droit communautaire» Revue juridique de l'environnement, 2008, pp. 410-413; Sonja BOELAERT-SUOMINEN, "The European Community, the Court of Justice and the Law of the Sea», International Journal of Marine and Coastal Law, vol. 23, núm. 4, 2008, pp. 699-713; Panos KOUTRAKOS, «The interpretation of mixed-agreements under the preliminary reference procedure», European Foreign Affairs Review, núm. 7, 2002, pp. 25-52. Con carácter más general, Nikos LAVRANOS, Decisions of International Organizations in the European and Domestic Legal Order of selected EU Member States, Europa Law Publishing, Groningen, 2004.

49 Sentencia del Tribunal de Primera Instancia Kupferberg, C-104/81, EU:T:2002:2. apdo. 14.

50 Sentencia del Tribunal de Justicia Comisión/Irlanda,C-459/03, ECLI:EU:C:2006:345, apdo. 132 en relación con los apdos. 123-125. 
$\mathrm{El}$ art. $282 \mathrm{CNUDM}$ incorpora una regla particular aplicable a las situaciones de "conexidad» de los procedimientos jurisdiccionales internacionales. Se deduce de esta disposición que un acuerdo general, regional o bilateral, anterior o posterior a la CNUDM, en el que las partes en una controversia hayan aceptado la jurisdicción de un órgano judicial o arbitral, tiene por efecto excluir los procedimientos previstos en la propia Convención. No obstante, en su razonamiento el Tribunal de Justicia incorporaba una determinada interpretación del art. 282 CNUDM no exenta de polémica, distinta de la realizada por el TIDM, sin incluir mención alguna al tratamiento recibido por el art. en la jurisprudencia internacional. En efecto, el TIDM había desarrollado previamente en el mismo asunto una interpretación en virtud de la cual el art. 282 CNUDM no resultaría aplicable a los supuestos de conexidad entre los mecanismos de arreglo jurisdiccional previstos en la parte XV de la CNUDM y los procedimientos previstos en los tratados de la Unión. Así se deduce, en efecto, del razonamiento realizado en su auto de medidas provisionales, de 3 de diciembre de 2001, en el que asumiendo una concepción formal del objeto de la controversia ${ }^{51}$, defiende la existencia separada de los derechos y obligaciones derivados de la CNUDM y considera que los tratados de la Unión «deal with disputes concerning the interpretation or application of those agreements, and not with disputes arising under the Convention ${ }^{52}$.

51 Un desarrollo doctrinal de esta concepción puede encontrarse en CAZALA, op. cit., nota 45, pp. 505 y ss. Asimismo, en MALJEAN-DUBOIS Y MARTIN, op. cit., nota 46, p. 45.

52 The Mox Plant Case (Ireland v. United Kingdom). Request for provisional measures, case núm. 10, 3 December 2001, apdo. 49. En su Opinión Separada, los jueces Wolfrum y Treves ofrecen desarrollos de esta línea de argumentación.

En general, esta interpretación del art. 282 CNUDM ha sido criticada por la doctrina y es, a su vez, distinta de la realizada en el laudo arbitral dictado en el asunto del atún de aleta azul. La aplicación del art. 282 fue aceptada por el tribunal arbitral, que consideró el Convenio para la Conservación del Atún de Aleta Azul Meridional de 1993 (CCSBT) como un acuerdo complementario de la CNUDM y se estimó artificial todo intento de identificar dos controversias distintas, de forma consistente con el art. 30 del Convenio de Viena sobre Derecho de los Tratados de 1969 (Southern Bluefin Tuna Case (Australia and New Zealand v. Japan), Award on Jurisdiction and Admissibility rendered by the Arbitral Tribunal constituted under Annex VII of the United Nations Convention on the Law of the Sea, August 4, 2000, apdo. 52). Al respecto, Barbara KWIATKOWSKA, «The Ireland v United Kingdom (Mox Plant) Case: Applying the Doctrine of Treaty Parallelism», The International Journal of Marine and Coastal Law, vol. 18, núm. 1, 2003, pp. 1-58; Robin CHURCHILL y R. Scott, «The MOX Plant Litigation: The First Half-Life», International and Comparative Law Quarterly, núm. 53, 2004, pp. 643-676; Volker RÖBEN, «The Order of 
Esta posición se entiende basada en un modelo de relación entre el derecho internacional y el derecho de la Unión, en virtud del cual ambos ordenamientos jurídicos tienen una existencia separada y la primacía del derecho de la Unión se impone como una necesidad constitucional ${ }^{53}$.

En este complejo contexto, destaca el posicionamiento adoptado por el Tribunal Arbitral, constituido en virtud del anexo VII de la CNUDM como juez competente en virtud del art. 287 CNUDM para conocer de la controversia sobre la fábrica de Mox. Aunque se le reprochara que ofreciera poca información sobre el alcance del art. 282 de la CNUDM, y que no ejerciera la competencia que formalmente ostentaba recurriendo a una afirmación radical de la autonomía de los ordenamientos jurídicos en presencia ${ }^{54}$, puede entenderse que actuó con buen criterio al procurar una coordinación de ambos sistemas inspirada en la idea de una buena administración de justicia. Formalmente, el TADM pudo haberse considerado facultado para dirimir sobre el alcance de la atribución de competencias por los Estados miembros a la Unión Europea, procediendo en consecuencia a la interpretación y aplicación de la declaración de competencias formulada por la $\mathrm{CE}$ al concluir la CNUDM. Sin embargo, en un momento en el que la Comisión había interpuesto ya el recurso por incumplimiento contra Irlanda, el TADM se mostraba consciente de la oportunidad de evitar — recurriendo a la aplicación del art. 282 de la CNUDM-, interferencias en el funcionamiento interno del derecho de la Unión. Consecuentemente, consideró que no era oportuno proseguir el procedimiento habida cuenta del riesgo de decisiones contradictorias y teniendo

the UNCLOS Annex VIII Arbitral Tribunal to Suspend Proceedings in the Case of the MOX Plant at Sellafield: How Much Jurisdictional Subsidiarity?», Nordic Journal of International Law, núm 73, 2004, pp. 223-245; Paolo TERRILE, «L'ordinanza del Tribunale del Mare nel caso Mox Plant», Il Diritto Marittimo, 2003, pp. 1243-1248; Philippe WECKEL, «Ordonnace du 24 juin 2003 (suspensión de l'instance et mesures conservatoires)», Revue Générale de Droit Internacional Public, vol. 107, núm. 4, 2003, pp. 984-994; 2005; «Les premieres applications de l'article 290 de la Convention sur le droit de la mer relative à la prescription de mesures conservatoires», Revue Générale de Droit Internacional Public, núm. 109 (4), 2005, pp. 829-857.

53 Martti KOSKENIEMMI, "Constitutionalism, Managerialism and the Ethos of Legal Education», European Journal of Legal Studies, vol. 1, núm. 1, 2007. En relación con las críticas suscitadas por la concepción de la autonomía del derecho de la Unión asumida por el Tribunal de Justicia en los asuntos Kadi o Intertanko, véase Jan WOUTERS; Jed ODERMATT y Thomas RAMOPOULOS, Worlds Apart? Comparing the Approaches of the European Court of Justice and the EU Legislature to International Law, Leuven Centre for Global Governance Studies, Working Paper num. 96.

54 CAZALA, op. cit., nota 46, pp. 656 y ss. 
presentes consideraciones relativas al respeto mutuo y a las reglas de cortesía entre órganos judiciales ${ }^{55}$. Decidió así suspender el curso del procedimiento recurriendo a lo que algunos autores han calificado como una suerte de «excepción prejudicial $»^{56} \mathrm{o}$ "excepción de conexidad» ${ }^{57}$.

Para autores como Long ${ }^{58}$, la interpretación expansiva de su monopolio jurisdiccional en virtud del art. 344 TFUE realizada por el Tribunal de Justicia en este asunto, se justificaría atendiendo al mayor nivel de garantías que comparativamente ofrece el sistema jurisdiccional de la Unión y el conjunto de mecanismos de control del cumplimiento del derecho de la Unión, en particular la imposición de sanciones en caso de incumplimiento de las sentencias del TJUE o de la obligación de informar a la Comisión de las medidas adoptadas para la transposición de directivas, previstas en el art. 260 TFUE. No obstante, dicha apreciación remite en términos prácticos a las funciones de vigilancia de la Comisión ${ }^{59}$, dada la pasividad mostrada por los Estados para interponer el recurso por incumplimiento ante el Tribunal de Justicia en virtud del art. 259 TFUE $^{60}$.

La interpretación más restrictiva del art. 344 TFUE en relación con el art. 282 CNUDM ha sido, en cambio, defendida por el juez Treves, quien se ha mostrado partidario de un recurso residual al sistema jurisdiccional de la Unión para la solución de controversias marítimas entre Estados miembros; esto es, limitado a los casos de acuerdos específicos que carezcan de un sistema jurisdiccional propio de solución de controversias. Ofrece como ejemplo la disputa relativa a la aplicación del Protocolo de Atenas de 18 de mayo de 1980 sobre la polución de origen telúrico a la Convención de Barcelona de 16

55 The Mox Plant Case, Ireland v. United Kingdom, Order num. 3, Suspension on proceedings on jurisdiction and merits, and request for further provisional measures, 24 June 2003, para. 28. Tras tener conocimiento del pronunciamiento del TJCE en su sentencia de 30 de mayo de 2006, el TADM dictó un auto de suspensión de las obligaciones relativas a la presentación de informes que había impuesto a las partes en sus autos de 24 de junio de 2003 y 14 de noviembre de 2004. El 6 de junio de 2008 decide poner fin al procedimiento.

56 WECKEL, op. cit., nota 52, p. 986.

57 KERBRAT, op. cit., nota 46.

58 LONG, op. cit., nota 23.

59 Como ejemplo práctico, se señalan las sanciones impuestas a Francia, Sentencia del Tribunal General, T-121/07, Alstom v. Comisión, ECLI:EU:T:2011:69 o España Sentencia del Tribunal de Justicia Comisión v. España, C-278/01, EU:C:2003:635.

60 No obstante, uno de los pocos casos que pueden encontrarse está referido a una controversia en materia pesquera, Sentencia del Tribunal de Justicia Regina v. Robert Tymen, C-141/78, ECLI:EU:C:1981:303. 
de febrero de 1976 sobre la Protección del Mediterráneo ${ }^{61}$. Concretamente, rechaza la interpretación del art. 282 CNUDM realizada por el Tribunal de Justicia refiriéndose, literalmente, al impacto negativo que esta jurisprudencia podría tener sobre la gran empresa de unificación del derecho y la cooperación internacional que constituye la $\mathrm{CNUDM}^{62}$.

\section{LA PRÁCTICA DE LA UNIÓN EUROPEA ANTE EL TIDM: ESPECIAL REFERENCIA AL PROCEDIMIENTO CONSULTIVO PROMOVIDO POR LA COMISIÓN SUBREGIONAL DE PESCA (ASUNTO NÚM. 21)}

El Reglamento del TIDM incluye previsiones específicas sobre la eventual participación de la Unión Europea en un procedimiento y la designación de jueces ad $h o c^{63}$, ofreciendo soluciones pragmáticas aunque poco favorables para la Unión. Se ha considerado que este hecho podría explicar tanto la inexistencia de una declaración de aceptación de la competencia del TIDM por parte de la UE como su acuerdo con Chile para someter la controversia relativa al asunto del Pez Espada a una sala $a d h o c^{64}$. Este ha sido el único asunto contencioso ante el TIDM en el participó la Unión Europea —entonces Comunidad Europea-. Aunque concluyó con un acuerdo entre las partes, el caso alentó la percepción de que el TIDM podía aportar su contribución a la promoción de soluciones diplomáticas y el arreglo de controversias marítimas en asuntos de interés para la UE y los Estados miembros.

61 Sentencia del Tribunal de Justicia, Comisión v. Francia, C-239/03, ECLI:EU:C:2004:598.

62 «Est-il de l'intérêt de la communauté internationale dans son ensemble et même de l'UE et des Etats membres que l'exemple donné soit suivi et que d'autres groupes d'Etats peut-être moins fidèles au droit de la mer tel que contenu dans la Convention, adoptent des mécanismes de règlement qui leur seraient propres? Je ne le crois pas. Le droit de la mer doit à mon avis rester strictement lié au droit international général notamment pour ce qui est de la solution arbitrale et judiciaire des différends. Toute dérive régionale ou régionaliste peut être dangereuse» (TREVES, op. cit., nota 14, p. 343).

63 La Unión no podría designar un juez ad hoc si en la formación del Tribunal figura un juez de nacionalidad de alguno de los Estados miembros. A la inversa, la parte contraria puede designar un juez ad hoc si en la formación del Tribunal figura un juez de la nacionalidad de un Estado miembro de la Unión. Para las situaciones más complejas en las que pueda figurar en la formación del Tribunal más de un juez de la nacionalidad de Estados miembros de la Unión, el presidente tras consultar con las partes puede pedir a uno o más jueces que se retiren (art. 22 del Reglamento del TIDM).

64 TREVES, op. cit, nota 14, p. 341. 
Posteriormente, la Unión Europea ha participado en el primer procedimiento consultivo suscitado ante el pleno del TIDM ${ }^{65}$. El 28 de marzo de 2013, el TIDM recibió una solicitud de opinión consultiva presentada por la Comisión Subregional de Pesca (CSRP) ${ }^{66}$; una organización regional de cooperación pesquera establecida por el Convenio de Dakar de 29 de marzo de 1995 del que forman parte Cabo Verde, Gambia, Guinea, Guinea-Bissau, Mauritania, Senegal y Sierra Leona. De conformidad con el art. 138 (3), en relación con el art. 133 (3) del Reglamento, el TIDM invitó a diversas organizaciones internacionales y los Estados parte a presentar observaciones escritas ${ }^{67}$. Asimismo, nueve Estados parte ${ }^{68}$, además de la Unión Europea, comunicaron su voluntad de participar en la fase oral del procedimiento.

65 Previamente, la Sala de Controversias de los Fondos Marinos emitió una opinión consultiva, el 1 de febrero de 2011, a petición del Consejo de la Autoridad Internacional de los Fondos Marinos, en relación con las responsabilidades y obligaciones de los Estados que auspician a personas o entidades en el marco de las actividades desarrolladas en la ZIFMO.

Request for an Advisory Opinion Submitted by the Sub-Regional Fisheries Commission (SRFC), ITLOS, Advisory Opinion of 2 April 215. La solicitud de opinión consultiva fue remitida en virtud de una decisión adoptada por la Conferencia de Ministros de dicha organización en su $14^{\circ}$ período de sesiones, el 27-28 de marzo de 2013. En la primera fase, más de 20 Estados —Arabia Saudí, Alemania, Nueva Zelanda, China, Somalia, Irlanda, Estados Federados de Micronesia, Australia, Japón, Portugal, Chile, Argentina, Reino Unido, Tailandia, Dinamarca, Cuba, Francia, España, Montenegro, Suiza y Sri Lanka — presentaron observaciones escritas. También Estados Unidos, Estado no parte en la Convención, remitió observaciones escritas y el TIDM decidió hacerlas públicas en una sección separada denominada Estados parte en el Acuerdo sobre Stocks de Peces Transzonales de 1995, y tomarlas en consideración como parte del caso. También la Unión Europea como entidad parte presentó sus observaciones que han sido incluidas por el Tribunal en la misma sección que las de los Estados parte. En otra lista figuran las seis organizaciones internacionales que presentaron observaciones: The Forum Fisheries Agency, the International Union for Conservation of Nature and Natural Resources (IUCN), the Caribbean Regional Fisheries Mechanism, the United Nations, the Food and Agriculture Organization of the United Nations (FAO), the Central American Fisheries and Aquaculture Organization.

En la segunda fase, cuatro Estados parte —Dinamarca, Nueva Zelanda, Tailandia y Reino Unido-, además de la Unión Europea, presentaron nuevas observaciones. También lo hizo la Comisión Subregional de Pesca. Adicionalmente, en ambas etapas la organización the World Wide Fund for Nature solicitó permiso para presentar un amicus curiae, como efectivamente hizo.

68 Argentina, Australia, Chile, Alemania, Estados federados de Micronesia, Nueva Zelanda, España, Tailandia y Reino Unido. 
Teniendo en cuenta la naturaleza de las cuestiones jurídicas sometidas al TIDM $^{69}$ y el hecho de que se incardinan materialmente en un ámbito de competencia exclusiva de la Unión de acuerdo con el art. 3 (1) (d) TFUE —en particular, la gestión y conservación de recursos pesqueros ${ }^{70}$-, las disposiciones de la parte XV de la CNUDM en materia de solución de controversias y las reglas procesales vigentes ante el TIDM, el derecho de la UE a intervenir en el procedimiento para la presentación de observaciones escritas y orales no suscitaba dudas. Más concretamente, la opinión consultiva versaba sobre el contenido y alcance de las obligaciones y responsabilidades de los Estados costeros y los Estados de pabellón, así como de las organizaciones internacionales competentes, en materia de pesca ilegal, no declarada y no regulada (INDNR). Se constata que esta materia está comprendida en el ámbito de aplicación del conjunto de disposiciones de la CNUDM, el Acuerdo de Cumplimiento de la FAO y el Acuerdo de las Naciones Unidas sobre las Poblaciones de Peces Transzonales y las Pobla-

69 Las cuestiones jurídicas sometidas al TIDM, quedaron así formuladas:

1. What are the obligations of the flag State in cases where illegal, unreported and unregulated (IUU) fishing activities are conducted within the Exclusive Economic Zones of third party States?

2. To what extent shall the flag State be held liable for IUU fishing activities conducted by vessels sailing under its flag?

3. Where a fishing license is issued to a vessel within the framework of an international agreement with the flag State or with an international agency, shall the State or international agency be held liable for the violation of the fisheries legislation of the coastal State by the vessel in question?

4. What are the rights and obligations of the coastal State in ensuring the sustainable management of shared stocks and stocks of common interest, especially the small pelagic species and tuna? (Request for Advisory Opinion, with as annex the Resolution of the Conference of Ministers of the Sub-Regional Fisheries Commission (SRFC), Apr. 2, 215, disponible en https://www.itlos.org/en/cases/list-of-cases/case-no-21).

70 De hecho, la Unión Europea ha concluido acuerdos de asociación en materia de pesca con varios de los Estados miembros de la CSRP y ha celebrado protocolos con dos de ellos que conceden acceso a la pesca a cambio de una contribución financiera. La mayor parte de estos acuerdos contienen una disposición comparable al art. 5, apdo. 4, del Acuerdo de Asociación en el Sector Pesquero entre la Comunidad Europea y la República de Cabo Verde (DO 2006, L 414, p. 3), conforme al cual «la Comunidad se compromete a adoptar todas las medidas pertinentes para garantizar la observancia de las disposiciones del presente Acuerdo por parte de los buques comunitarios, así como de la legislación por la que se rige la pesca en las aguas sometidas a la jurisdicción de Cabo Verde». 
ciones de Peces Altamente Migratorios — todos ellos instrumentos en los que es parte la Unión Europea-, así como de los acuerdos de colaboración celebrados entre la Unión y los Estados miembros de la CSRP, integrados en el ordenamiento jurídico de la Unión en virtud del art. 216 (2) TFUE ${ }^{71}$. Por otro lado, esta materia es objeto de una regulación detallada en el derecho de la Unión, que fue reforzada en 2008 para tener en cuenta sus compromisos internacionales.

En el seno del COJUR se gestó un acuerdo político en el sentido de que la Comisión representaría a la Unión en relación con las cuestiones jurídicas sometidas al TIDM en tanto que los Estados miembros podrían presentar sus observaciones sobre la cuestión de la jurisdicción consultiva del TIDM. Sobre esta última cuestión, los Estados miembros mantenían, de hecho, posiciones muy divergentes. Finalmente, la Comisión presentó observaciones escritas respondiendo a las cuatro cuestiones jurídicas suscitadas e incorporando argumentos sobre jurisdicción y, de un modo más directo, admisibilidad. Paralelamente, varios Estados miembros -Alemania, Bélgica, España, Francia, Irlanda, Portugal y Reino Unido- presentaron observaciones escritas sobre la jurisdicción del TIDM, la admisibilidad y los criterios de oportunidad en el ejercicio de la jurisdicción consultiva en el caso concreto. No obstante, algunos Estados, como Francia, abordaron también en su escrito aspectos relativos a las dos primeras cuestiones jurídicas sometidas al TIDM.

Ciertamente la cuestión de la existencia y alcance de la jurisdicción consultiva del TIDM ha constituido una de las cuestiones más controvertidas. Las observaciones escritas presentadas por varios Estados miembros ofrecen ejemplos de las posiciones asumidas sobre este punto, en términos más amplios, por el conjunto de los Estados y organizaciones que participaron en el procedimiento. Así, Alemania, Estado sede del TIDM, reconoce en un breve escrito la jurisdicción consultiva del Tribunal. Sin embargo, la mayoría de Estados miembros que presentaron observaciones escritas — con inclusión de España - consideraban que el TIDM no ostenta jurisdicción consultiva de carácter general. Sus principales argumentos eran que dicha jurisdicción no le ha sido atribuida expresamente en las disposiciones de la CNUDM ni el Estatuto del TDIDM y el ejercicio de la jurisdicción consultiva no forma parte de los poderes inherentes al ejercicio de la función jurisdiccional, como confirman un análisis de la práctica basado en un estu-

71 En este sentido, la Sentencia del Tribunal de Justicia Air Transport Association of America y otros, C366/10, EU:C:2011:864, apdo. 73 y jurisprudencia citada. 
dio comparativo de los diferentes tribunales internacionales ${ }^{72}$ y la opinión mayoritaria de la doctrina ${ }^{73}$.

No obstante, una previsión específica fue posteriormente incorporada en el art. 138 del Reglamento del TIDM $^{74}$. Como consecuencia de ello, los debates se centraron en la interpretación de esta disposición en relación con el art. 21 del Estatuto, como único argumento plausible para establecer por vía interpretativa una base jurídica para la jurisdicción consultiva del $\mathrm{TIDM}^{75}$. No obstante, tanto la interpretación literal — particularmente aten-

72 Así, la facultad de emitir opiniones consultivas ha quedado formalmente reconocida en el caso de la Corte Permanente de Justicia Internacional —art. 14 (3) del Pacto de la Sociedad de Naciones_- la Corte Internacional de Justicia —art. 96 (2) de la Carta de las Naciones Unidas-, el Tribunal Europeo de Derechos Humanos - art. 47 y 48 del CEDH y el Protocolo núm. 16-, la Corte Interamericana de Derechos Humanos — art. 64 de la Convención Interamericana de Derechos Humanos-, la Corte Africana de Derechos Humanos y de los Pueblos — art. 4 del Protocolo a la Carta Africana de Derechos Humanos y de los Pueblos-. Asimismo, el Tribunal de Justicia de la Unión Europea —art. 218 TFUE, apdo. 11- y la Corte de Justicia de la Comunidad Económica de los Estados de África Occidental —art. 10 del Protocolo sobre la Corte de Justicia de ECOWAS-. Un análisis de las reglas y el alcance de la jurisdicción consultiva de estos tribunales en Karin OELLERS-FRAM, "Lawmaking Through Advisory Opinions?», German Law Journal, vol. 12, núm. 5, 2011, pp. 1033-1056.

73 En los comentarios más autorizados a la CNUDM se considera lo siguiente: «The tribunal itself has no advisory jurisdiction, and the advisory jurisdiction of the Chamber is limited to legal questions that may be referred to it only by the Assembly or Council, within the scope of their activities» -Myron NORDQUITS et al. (eds.), United Nations Convention on the Law of the Sea 1982: A Commentary, Vol. VI, Martinus Nijhoff, Drodrecht, 1991, p. 64; vol. V, p. 416-.

74 Concretamente, el apdo. 1 del art. 138 del Reglamento del TIDM establece lo siguiente: «The Tribunal may give an advisory opinion on a legal question if an international agreement related to the purposes of the Convention specifically provides for the submission to the Tribunal of a request for such an opinion».

75 Esta disposición establece lo siguiente: «The jurisdiction of the Tribunal comprises all disputes and all applications submitted to it in accordance with this Convention and all matters specifically provided for in any other agreement which confers jurisdiction on the Tribunal». En relación con su interpretación, José Luis JESUS, The Rules of the International Tribunal of the Law of the Sea: A Commentary, Chandrasekhara RAO y Philippe GAUTIER (eds.), Nijhoff, 2006, pp. 393-394. En general, Miguel GARCÍA GARCÍA-REVILLO, The Contentious and Advisory Jurisdiction of the International Tribunal for the Law of the Sea, Brill/Nijhoff, Leiden/Boston, 2016; Ki-Jun YOU, «Advisory Opinions of the International Tribunal for the Law of the Sea: Article 138 
diendo a la versión francesa- como sistemática —en relación con el art. 288 CNUDM-, al igual que los trabajos preparatorios, parecen apuntar en un sentido contrario.

En su opinión consultiva de 2 de abril de 2015, el TIDM ha acogido la interpretación del art. 21 del Estatuto más amplia y favorable a la afirmación de su jurisdicción consultiva ${ }^{76}$. El centro del debate se encontraba en la interpretación del término «asuntos» especialmente previstos en otros acuerdos internacionales, distintos de la CNUDM, que confieran competencia al TIDM. A juicio del propio Tribunal está expresión no se limita al concepto de disputas y puede hacerse extensible a las opiniones consultivas especialmente previstas en tales acuerdos ${ }^{77}$. Con todo, parece que la argumentación ofrecida por el TIDM no garantiza suficientemente el fin del desacuerdo sobre esta cuestión. De hecho, en su voto separado el juez Lucky ha defendido la necesidad de una enmienda formal del art. 21 del Estatuto con el fin de excluir, en el futuro, cualquier polémica sobre el fundamento de la jurisdicción consultiva del TIDM. ${ }^{78}$.

of the Rules of the Tribunal Revisited", Ocean Development and International Law, num. 39, 2008, pp. 360-371; Yosifhumi TANAKA, "Reflections on the Advisory Jurisdiction of ITLOS as a Full Court: the ITLOS Advisory Opinion of 2015», Law and Practice of International Courts and Tribunals, vol. 14, núm. 2, 2015, pp. 318339; Tafsir Mlalick NDIAYE, "The Advisory Function of the International Tribunal for the Law of the Sea», Chinese JIL, 2010, pp. 565-587; Helmut TÜRK, "Advisory Opinions and the Law of the Sea», en The Challenges of Contemporary International Law and International Relations, Liber Amicorum Dr Ernest Etric; M. P. POGADNI et al. (eds.), European Law Faculty of Nova Guinea, 2013. En términos más generales, Rudiger WOLFRUM, «Panel II: Advisory Opinions: Are they a Suitable Alternative for the Settlement of International Disputes?», en Roudiger WOLFRUM y Ina GÄTZSCHMANN, International Dispute Settlement: Room for Innovations, 2013, pp. 33-123; Michael WOOD, «Advisory Jurisdiction: Lessons from Recent Practice», en Holger HESTERMEYER et al., Coexistence, Cooperation and Solidarity: liber amicorum Rüdiger Wolfrum, Nijhoff, Leiden, 2012, Volume 2, pp. 1833-1849.

Jianjun GAO, "The ITLOS Advisory Opinion for the SRFC», Chinese Journal of International Law, vol. 14, núm. 4, 2015, pp. 709-733; Massimo LANDO, «The Advisory Jurisdiction of the International Tribunal for the Law of the Sea: Comments on the Request for an Advisory Opinion Submitted by the Sub-Regional Fisheries Commission", Leiden Journal of International Law, vol. 29, núm. 2, 2016, pp. 441461.

77 Request for an Advisory Opinion Submitted by the Sub-Regional Fisheries Commission (SRFC), ITLOS, Advisory Opinion of 2 April 2015, apartados 56-58 (www. itlos.org/en/cases/list-of-cases/case-no-21).

78 Advisory Opinion, Separate Opinion of Judge Lucky, apdo. 28. 
Por otra parte, el TIDM reitera los prerrequisitos que establece el art. 138 del Reglamento ${ }^{79}$. En respuesta a las preocupaciones expresadas por diversos Estados sobre la cuestión de los limites inherentes al ejercicio de este tipo de jurisdicción consultiva especial ${ }^{80}$, el TIDM se limita a reproducir el criterio utilizado por la $\mathrm{CIJ}$ en su opinión consultiva sobre la legalidad del uso de armas nucleares y expresar su propósito de limitar, en este caso, el ejercicio de su jurisdicción consultiva a la ZEE de los Estados parte de la SCRP ${ }^{81}$.

En cuanto al contenido de las cuestiones jurídicas formuladas por la Comisión Subregional de Pesca, como ya hemos anticipado, estas versaban sobre el contenido y alcance de las obligaciones y responsabilidades de los Estados costeros y Estados de pabellón, así como de las organizaciones internacionales competentes —en particular, la Unión Europea - en relación con las actividades de pesca ilegal, no declarada y no regulada (INDNR) ${ }^{82}$. En particular, la tercera de las cuestiones jurídicas mencionadas afectaba de un modo particularmente importante a la UE, lo que explica la atención otorgada al hecho de que, en sus primeras observaciones presentadas por escrito en representación de la Unión, la Comisión no incluyera referencias al Proyecto de artículos de la CDI sobre la responsabilidad internacional de las organizaciones internacionales $^{83}$. De hecho, se considera que el TIDM ha dado una respuesta de in-

79 Request for an Advisory Opinion Submitted by the Sub-Regional Fisheries Commission (SRFC), ITLOS, apdo. 60.

80 Véanse, al respecto, las observaciones escritas y orales presentadas por Michael WOOD por parte del Reino Unido (ITLOS/PV.14/C21/3/Rev.1 4 September 2014 a.m., pp. 23-25).

81 Request for an Advisory Opinion Submitted by the Sub-Regional Fisheries Commission (SRFC), ITLOS, Advisory Opinion of 2 April 2015, apartados 67-69.

82 Al respecto, Talfsir Malick NDIAYE, «Illegal, Unreported and Unregulated Fishing: Responses in General and in West Africa», Chinese Journal of International Law, núm. 10, 2011, pp. 373-405; V. A. Mayer FEITOSA VENTURA, «Tackling illegal, unregulated and unreported fishing: the ITLOS Advisory Opinion on Flag State Responsibility for IUU fishing and the principle of due diligence», Brasilian Journal of International Law, vol. 12, núm. 1, 205, pp. 50-68; C. COSTA RIVEIRA, Comentário à Opinião Consultiva 21 do Tribunal Internacional para o Direito Do Mar [02/04/2015] (Responsabilidade do Estado de Bandeira pela pesca ilícita, não declarada ou não regulamentada)», Brasilian Journal of International Law, vol. 12, núm. 1, 205, pp. 25-32.

83 Frank HOFFMEISTER, «Litigating against the European Union and Its Member States. Who Responds under the ILC's Draft Articles on International Responsibility of International Organizations?», European Journal of International Law, vol. 21, núm. 3, 2010, pp. 723-747. 
terés para el desarrollo de la teoría de la responsabilidad de las organizaciones internacionales de integración ${ }^{84}$ acogiendo, en relación con las reglas de atribución, el criterio de la competencia ${ }^{85}$ frente al criterio del órgano adoptado con carácter general por la $\mathrm{CDI}^{86}$.

En todo caso, resultan evidentes las ramificaciones de orden general que presentaban las cuestiones jurídicas formuladas en materia de responsabilidad internacional, tanto en relación con la atribución como en relación con las consecuencias jurídicas de dicha atribución. Teniendo en cuenta este hecho, se comprende que la existencia de competencia exclusiva de la Unión Europea en materia pesquera no bastase para excluir la percepción que tenían los Estados miembros de que las cuestiones jurídicas sometidas al TIDM afectaban en términos más amplios a sus intereses. Las tensiones surgidas en este sentido se proyectaron al marco institucional dando lugar a un contencioso entre el Consejo y la Comisión ante el Tribunal de Justicia de la Unión Europea.

\section{LA DEFINICIÓN DE LA POSICIÓN Y LA REPRESENTACIÓN DE LA UNIÓN EUROPEA ANTE LOS TRIBUNALES INTERNACIONALES}

En el ámbito interno de la Unión Europea se produjo un desacuerdo entre las instituciones sobre la competencia para decidir acerca del contenido de las observaciones presentadas en representación de la Unión ante el TIDM. El resultado fue la introducción de un recurso de anulación en el que el Consejo impugnaba la Decisión de la Comisión de 29 de noviembre de 2013 de presentar una «declaración escrita de la Comisión Europea en representación de la Unión Europea» al TIDM sin su previa aprobación, si bien no solicitaba en su recurso la anulación de dicha declaración. El primer motivo formulado en apoyo de su pretensión era que, al adoptar la Decisión impugnada, la Comisión violó el principio de la distribución de poderes consagrado en el

84 PAASIVIRTA, op. cit., nota 25. En relación con el tema de la responsabilidad internacional de las organizaciones de integración, Pieter Jan KKUIJPER y Esa PAASIVIRTA, «EU International Responsibility and Its Attribution: From Inside Looking Out», en Malcon EVANS y Panos KOUTRAKOS (eds.), The International Responsibility of the European Union, Amsterdam Center for European Law and Governance (ACELG), 2013, pp. 35-71, p. 54.

85 Request for an Advisory Opinion Submitted by the Sub-Regional Fisheries Commission (SRFC), ITLOS, Advisory Opinion of 2 April 2015, apdos. 172-174.

86 Art. 6 del Proyecto de Arts. sobre la Responsabilidad de las Organizaciones Internacionales, CDI, 2011. La AGNU aprobó ese proyecto en su resolución 66/100, de 9 de diciembre de 2011. 
art. 13 (2) TUE y, consecuentemente, el principio de equilibrio institucional en relación con el art. 218 (9) TFUE y el art. 16 (1) TUE. Como segundo motivo, el Consejo sostuvo que, al tomar las medidas que dieron lugar a la adopción de la Decisión impugnada, la Comisión violó el principio de cooperación leal consagrado en el art. 13 (2) TUE. Este contencioso fue resuelto por el Tribunal de Justicia en su sentencia de 6 de octubre de $2015^{87}$, que aporta una nueva contribución a la configuración del principio de la unidad en la representación internacional de la $\mathrm{UE}^{88}$.

En términos generales, la cuestión de la representación de las partes en los procedimientos ante órganos judiciales internacionales es contemplada en términos muy generales y flexibles. En el caso del TIDM, las previsiones correspondientes se encuentran en los arts. 41 (2) y 42 de su Reglamento, redactadas en términos muy similares a las que figuran en el art. 53 del Reglamento de la $\mathrm{CIJ}^{89}$. En este caso, la Comisión defendió su poder de representación de la Unión en los procedimientos judiciales en virtud del art. 335 TFUE. Varios Estados coadyuvantes argumentaron, sin embargo, que dicho art. se referiría únicamente a los procedimientos sustanciados ante los órganos

87 PAASIVIRTA, op. cit., nota 24, pp. 1045-1071; Soledad R. SÁNCHEZ TABERNERO, «Swimming in a Sea of Courts: The EU's Representation Before International Tribunals», European Papers, vol. 1, núm. 2, 2016, pp. 751-758; Denys SIMON, «Représentation de l'Union», Europe, núm.12, Décembre 2015, pp. 15-16.

88 Una primera formulación del principio en la jurisprudencia del TJUE, se encuentra ya en el Dictamen 1/94, EU:C:1994:384, punto XIX: "Cuando la materia de un Convenio internacional esté comprendida en parte dentro de la competencia de la Comunidad y en parte dentro de la de los Estados miembros, la exigencia de unidad en la representación internacional de la Comunidad requiere garantizar una estrecha cooperación entre estos últimos y las Instituciones comunitarias, tanto en el proceso de negociación y de celebración como en la ejecución de los compromisos asumidos. Este deber de cooperación, se impone, de manera aún más imperiosa, en el caso de Acuerdos como los anexos al Acuerdo por el que se establece la Organización Mundial del Comercio, entre los cuales existe una relación indisoluble y para los que se ha establecido un sistema de solución de litigios que incluye un mecanismo de retorsión cruzada», Al respecto, Bernd MARTENCZUK, "The External Representation of the European Union: From Fragmentation to a Single European Voice?», en A. FISCHER-LESCANO, H. P. GASSER, T. MARAUHN y N. RONZITTI (eds.), Frieden in Freiheit, Festschrift für Michael Bothe, Geburtstag, Nomos, 2008, págs. 941 944; Jan WOUTERS, Frank HOFFMEISTER, Geert DE BAERE y Thomas RAMOPOULOS, The Law of EU External Relations: Cases, Materials, and Commentary on the EU as an International Legal Actor, Oxford University Press, 2013.

89 Al respecto, Chitharanjan F., AMERASHINGE, Jurisdiction of International Tribunals, Kluwer, The Hague, 2003, pp. 34-41. 
jurisdiccionales nacionales. Sin embargo, según el Tribunal de Justicia, se desprende de su jurisprudencia que el art. 335 TFUE constituye la expresión de un principio general en virtud del cual la Unión dispone de capacidad jurídica y está representada, a tal fin, por la Comisión ${ }^{90}$. Dicha función comprende la representación de la Unión en los procedimientos judiciales nacionales e internacionales.

Sin embargo, la aplicabilidad del art. 335 TFUE no bastaba para resolver la cuestión controvertida, que consistía en determinar si el contenido de las observaciones presentadas por la Comisión en representación de la Unión debía ser previamente aprobado por el Consejo. Ciertamente, los tratados establecen una distinción entre la representación internacional de la UE y la definición de las posiciones que deban adoptarse internacionalmente en su nombre. Para contextualizar mínimamente el problema, hay que recordar que este tipo de tensiones institucionales han tenido su expresión incluso en un ámbito como el de la OMC — en particular, en el marco del Comité 133-, en el que la actividad de la Unión como parte litigante y de la Comisión en representación de la Unión Europea se encuentra más desarrollada ${ }^{91}$. Un caso

90 Sentencia del Tribunal de Justicia Consejo/Comisión, C-73/14, EU:C:2015:663, apdo. 58. En este sentido, la sentencia del Tribunal de Justicia Reynolds Tobacco y otros c. Comisión, C131/03 P, EU:C:2006:541, apdo. 94.

91 En este sentido, puede tomarse como ejemplo de la tensión institucional referida, el asunto Comisión c. Alemania. El argumento esgrimido por Alemania consistía en considerar que, antes de emprender acciones por incumplimiento con uno de los acuerdos del GATT de la Ronda de Tokio, la Comisión debió esperar a que se lograra un consenso en el marco del Comité 133. El Tribunal de Justicia rechazó entonces este argumento considerando que su función era puramente consultiva (Sentencia del Tribunal de Justicia Comisión /Alemania, C 61/94, EU:C:1996:313). No obstante, como observaba el juez Rosas, persistían importantes problemas interpretativos; «[i]n fact, arguments have sometimes been expressed in the Council bodies that decisions taken to initiate proceedings in the WTO should be taken by the Council and not the Commission. There also seems to exist a certain assumption in the 133 Commission. There also seems to exist a certain assumption in the 133 Committee that it plays not only and advisory political role but also a formal role in the launching of new WTO cases on behalf of the Communities» (op. cit., p. 66). Es destacable, sin embargo, que la posibilidad que consagraba el art. 14 del Reglamento 3286/94 del Consejo, de 2 de diciembre de 1994 reservando a los Estados miembros el derecho de formular objeciones a la propuesta de la Comisión de iniciar un procedimiento en el marco OMC y remitir la propuesta al Consejo que podría modificarla por mayoría cualificada, no parece haber llegado a utilizarse en la práctica (Reglamento (CE) núm. 3286/94 del Consejo, de 2 de diciembre de 1994, por el que se establecen 
más reciente en el que también se manifestaron disfunciones importantes fue la falta de coordinación en MARSEC, si bien la composición y naturaleza de sus funciones es distinta a la de COMAR. En su Sentencia de 12 de febrero de 2009, el Tribunal de Justicia condena a Grecia y declara que ningún Estado tiene derecho a someter posiciones nacionales en el marco de una organización internacional sobre materias de competencia exclusiva de la Unión (Organización Marítima Internacional). No obstante, se suscita también un posible incumplimiento por parte de la Comisión de su deber de cooperación

procedimientos comunitarios en el ámbito de la política comercial común con objeto de asegurar el ejercicio de los derechos de la Comunidad en virtud de las normas comerciales internacionales, particularmente las establecidas bajo los auspicios de la organización Mundial del Comercio, DO L 349 de 31/12/1994 p. 0071-0078). En cualquier caso, dicho art. 14 fue suprimido con motivo de la modificación realizada en virtud del Reglamento 37/214, de 15 de enero de 2014 para garantizar la coherencia con las disposiciones introducidas por el Tratado de Lisboa, y sustituido por un nuevo art. 13 (2) que dispuso que cuando la Unión - como consecuencia de una denuncia de una cualquier particular que actúe en nombre de un sector económico o de cualquier empresa comunitaria o asociación que actúe en nombre de una o más empresas, o de una solicitud de un Estado miembro- siguiera procedimientos internacionales de consulta o de solución de litigios, la Comisión adoptará decisiones sobre la apertura, el desarrollo y la conclusión de dichos procedimientos (Reglamento (UE) núm. 37/2014 del Parlamento Europeo y del Consejo, de 15 de enero de 2014, por el que se modifican determinados reglamentos relativos a la política comercial común en lo referente a los procedimientos para la adopción de determinadas medidas, DO núm. L 18/1 de 21/1/2014). Asimismo, informará a los Estados miembros si decide iniciar, llevar a cabo o concluir procedimientos formales internacionales de consulta o de solución de litigios. La misma regulación mantiene el nuevo Reglamento (UE) 2015/1843 del Parlamento Europeo y del Consejo, de 6 de octubre de 2015 en su art. 14 (1), actualmente en vigor. Incumbe, pues, a la Comisión actuar respecto de los obstáculos al comercio que son adoptados o mantenidos por terceros países, en el marco de los derechos y obligaciones internacionales de la Unión, únicamente cuando los intereses de la Unión exijan una intervención. Al evaluar dichos intereses, la Comisión debe prestar la debida consideración a los puntos de vista expresados por todas las partes interesadas en los procedimientos (Reglamento (UE) 2015/1843 del Parlamento Europeo y del Consejo, de 6 de octubre de 2015, por el que se establecen procedimientos de la Unión en el ámbito de la política comercial común con objeto de asegurar el ejercicio de los derechos de la Unión en virtud de las normas comerciales internacionales, particularmente las establecidas bajo los auspicios de la Organización Mundial del Comercio, DO L 272 de 16.10.2015, p. 1/13). 
leal al negarse a incluir la propuesta controvertida en el Comité MARSEC, aunque este hecho no tiene entidad suficiente como para permitir a un Estado miembro tomar iniciativas susceptibles de afectar a las normas comunitarias dictadas para alcanzar los fines del Tratado ${ }^{92}$.

En primer lugar, como observábamos, el Consejo invocaba una posible vulneración del principio del equilibrio institucional consagrado en el art. 13 (2) TUE en relación con la vulneración de las prerrogativas del Consejo en el marco del art. 218 (9) TFUE ${ }^{93}$. En términos generales, cabe destacar la conflictividad constatada en torno a esta última disposición y la importancia de la labor interpretativa desarrollada por el Tribunal de Justicia como sucedió, por ejemplo, con la cuestión de las decisiones híbridas ${ }^{94}$.

En cualquier caso, el objeto de dicha disposición es establecer, en relación con el procedimiento de celebración de acuerdos internacionales, un procedimiento simplificado para la definición de las posiciones que deban adoptarse en nombre de la Unión en el contexto de su participación en un organismo creado por el acuerdo internacional de que se trate, cuando dicho organismo deba adoptar actos relativos a la aplicación o a la ejecución de éste. Ahora bien, el Tribunal de Justicia distingue entre la definición de la posición política de la Unión que haya de expresarse en un organismo internacional creado en virtud de un acuerdo y la presentación de obser-

92 Sentencia del Tribunal de Justica Comisión/Grecia, C-45/07 EU:C:2009:81, apdo. 28. Por analogía, la sentencia del Tribunal de Justicia Hedley Lomas, C5/94, EU:C:1996:205, apdo. 20 y la jurisprudencia citada. Lawrence BOISSON DE CHAZOURNES, «Compétences respectives de l'UE et des Etats membres en matière de sécurité maritime», $L e$ droit maritime français, 2010, pp. 671-676.

93 Dicha disposición establece lo siguiente: «El Consejo adoptará, a propuesta de la Comisión o del Alto Representante de la Unión para Asuntos Exteriores y Política de Seguridad, una decisión por la que se suspenda la aplicación de un acuerdo y se establezcan las posiciones que deban adoptarse en nombre de la Unión en un organismo creado por un acuerdo, cuando dicho organismo deba adoptar actos que surtan efectos jurídicos, con excepción de los actos que completen o modifiquen el marco institucional del acuerdo».

94 Sentencia del Tribunal de Justicia C-28/12, Comisión/Consejo, EU:C:2015:282. $\mathrm{Al}$ respecto, Soledad R. SÁNCHEZ-TABERNERO, «La ilegalidad de las decisiones híbridas en el marco de la celebración de acuerdos mixtos. Comentario de la sentencia TJUE de 24.04.2015 (Gran Sala), C-28/12 Comisión/Consejo», Revista de Derecho Comunitario Europeo, núm. 52, 2015, pp. 1057-1073. En términos más generales, Ricardo GOSALBO BONO, «Insuficiencias jurídicas e institucionales de la acción exterior de la Unión Europea», Revista de Derecho Comunitario Europeo, núm. 50, 2015, pp. 231-320. 
vaciones ante un tribunal internacional en el marco de un procedimiento judicial; en este caso, un procedimiento consultivo. Esta interpretación se ve, a su juicio, corroborada por el contexto y el objetivo en que se encuadra el art. 218 (9) TFUE. La situación suscitada en el procedimiento consultivo ante el TIDM es considerada expresamente por el Tribunal de Justicia distinta a la suscitada en la sentencia Alemania/Consejo sobre la posición que debía adoptarse en nombre de la Unión en un acuerdo del que esta no es parte —en particular, la Organización de la Viña y el Vino-, por medio de los Estados miembros, en relación con la adopción de recomendaciones en el seno del organismo creado por el acuerdo internacional en cuestión ${ }^{95}$. Ciertamente, se trata en este caso de la definición de una posición que debe exponerse en nombre de la UE ante un órgano jurisdiccional internacional al que se solicita una opinión consultiva cuya adopción es de competencia y responsabilidad exclusivas de los miembros de dicho órgano, que actúan con total independencia con respecto a las partes. Por tanto, el Tribunal de Justicia rechaza la aplicación del art. 218 (9) TFUE para definir la posición de la Unión Europea ante los tribunales internacionales atendiendo al principio de independencia en el ejercicio de la función judicial ${ }^{96}$. Esta línea de fundamentación permitiría concluir que la misma interpretación se hace extensible al caso de la representación de la Unión en un procedimiento contencioso ante un tribunal internacional.

Por otro lado, el Tribunal de Justicia afirma la inaplicabilidad del art. 218 (9) TFUE sin que sea necesario, a su juicio, examinar si una opinión consultiva del TIDM responde al concepto de «acto que surta efectos jurídicos» que figura en dicha disposición. Este problema ya se había suscitado en el asunto Alemania/Consejo, en el que dicho Estado defendió que la expresión debía interpretarse como referida a los actos de Derecho Internacional que sean vinculantes para la Unión. El Tribunal de Justicia consideró entonces que dicha disposición cubre los actos que surtan efectos jurídicos — ya sean vinculantes o no vinculantes- y se limitó a constatar la influencia determinante de las recomendaciones controvertidas en el contenido de la normativa de la Unión relativa a la organización común de los mercados vitivinícolas ${ }^{97}$.

95 Sentencia del Tribunal de Justicia RF de Alemania/Consejo, C-399/12 EU:C: 2013:107.

96 Sentencia del Tribunal de Justicia Consejo/Comisión, C-73714, EU:C:2015:663, apdo. 66.

97 Con carácter general, Paula GARCÍA ANDRADE, «The Distribution of Powers Between EU Institutions for Conducting External Affairs through Non-Binding Instruments», European Papers, vol. 1, núm. 1, 2016, pp. 115-125. 
También se ha considerado inaplicable el art. 16 (1) TUE invocado por el Consejo con el argumento de que, al presentar observaciones ante el TIDM sin su aprobación previa, la Comisión había usurpado las funciones legislativas que corresponden únicamente al Consejo. El Tribunal de Justicia precisa que el objeto de las observaciones que la Comisión presentó ante el TIDM no era definir una política en materia de pesca INDNR en el sentido del art. 16 (1) TUE, segunda frase, sino presentar al TIDM — sobre la base del análisis de las disposiciones internacionales y de la normativa de la Unión pertinentes - un conjunto de apreciaciones jurídicas que permitiera a dicho órgano jurisdiccional emitir una opinión consultiva con conocimiento de causa sobre las cuestiones que se le habían planteado ${ }^{98}$. Las consideraciones presentadas por la Comisión ante el TIDM — tanto sobre el contenido de las cuestiones jurídicas formuladas por la CSRP, como sobre las cuestiones de jurisdicción y admisibilidad- no responden a la definición de políticas en el sentido del art. 16 (1) TUE sino que son características de la participación en un procedimiento ante un órgano jurisdiccional ${ }^{99}$. Las consecuencias políticas para las relaciones entre la Unión y la CSRP que podían derivarse del contenido de las observaciones presentadas no modifican esta calificación.

El segundo motivo esgrimido por el Consejo y los Estados coadyuvantes consistía en la vulneración del principio de cooperación leal consagrado en el art. 13 (2) TUE, dado que consideraban que la Comisión debía haber presentado al Consejo una propuesta formal de decisión en la que se expusiera la posición que iba a adoptarse en nombre de la UE ante el TIDM. Ello comportaría también un incumplimiento de la obligación que el art. 17 (1) TUE impone a la Comisión de tomar las iniciativas adecuadas para promover el interés general de la Unión. El Tribunal de Justicia ha considerado reiteradamente el deber de cooperación leal como una manifestación concreta del principio de buena fe que, en este caso, se deriva del principio de unidad en la representación internacional de la Unión Europea al que ya se había referido el Tribunal en su Dictamen $2 / 91$ de 19 de marzo de $1993^{100}$. Dicho principio implica un deber de

98 Sentencia del Tribunal de Justicia Consejo/Comisión, C-73/14, EU:C:2015:663, apdo. 71.

99 Ibid., apdo. 73.

100 En efecto, observaba entonces que «cuando resulte que la materia de un acuerdo o de un convenio esté comprendida en parte dentro de la competencia de la Comunidad y en parte dentro de la de los Estados miembros, es necesario garantizar una estrecha cooperación entre estos últimos y las instituciones comunitarias tanto en el proceso 
información y consulta previas ${ }^{101}$ y una asociación estrecha entre las instituciones de la Unión y los Estados miembros en el proceso de negociación y de celebración de acuerdos internacionales, así como en el proceso de información y consulta y la ejecución de los compromisos que se han asumido en función de dichos acuerdos. En particular, se impone la necesidad de obtener una acción concertada a nivel internacional ${ }^{102}$. En la medida en que la construcción de este motivo de impugnación del acto era deudora del argumento de la aplicación del art. 218 (9) TFUE y del art. 16 (1) TUE, resultaría igualmente desestimado. El deber de cooperación leal debe ejercerse respetando los límites de las facultades que los tratados confieren a cada institución. La obligación dimanante del art. 13 (2) TUE no tiene entidad suficiente para modificar esas facultades ${ }^{103}$.

Tras considerar y rechazar el conjunto de los argumentos esgrimidos por el Consejo, el Tribunal de Justicia concluye no obstante su argumentación con una importante afirmación de principio. En tal sentido, afirma que «el principio de cooperación leal impone a la Comisión la obligación de consultar previamente al Consejo, cuando se proponga expresar posiciones en nombre de la Unión ante un tribunal internacional ${ }^{104}$. El cumplimiento de dicha obligación deberá apreciarse en las circunstancias del caso concreto y teniendo en cuenta los límites temporales que imponen las reglas de procedimiento. Se deduce, en todo caso, del razonamiento de la sentencia que la obligación de consultar no equivale a una obligación de obtener la aprobación formal previa del Consejo sobre el contenido de las observaciones que la Comisión presente ante los tribunales internacionales en representación de la UE. En el caso específico del procedimiento consultivo ante el TIDM, se ha considerado que la Comisión cumplió con

de negociación y de celebración como en la ejecución de los compromisos asumidos. Esta obligación de cooperar se deriva de la exigencia de unidad en la representación internacional de la Comunidad (Resolución 1/78, de 14 de noviembre de 1978, Rec. p. 2151, apartados 34 a 36, y Dictamen 2/91, antes citado, apdo. 36)», Dictamen del Tribunal de Justicia 1/94, EU:C:1994:384, apdo. CVII).

101 Sentencia del Tribunal de Justicia Consejo/Comisión, C-73/14, EU:C:2015:663.

102 Asuntos sobre los transportes por vía navegable. Sentencia del Tribunal de Justicia Comisión/Luxemburgo, C-266/03, EU:C:2005:341; Sentencia del Tribunal de Justicia Comisión/Alemania, C-433/03, EU:C:2005:462.

103 Sentencia del Tribunal de Justicia Parlamento/Consejo C48/14, EU:C:2015:91, apdo. 84.

104 Sentencia del Tribunal de Justicia Consejo/Comisión, C-73/14, EU:C:2015:663, apdo. 86. 
dicha obligación dado que presentó al Consejo un documento de trabajo revisado en diversas ocasiones para tener en cuenta las posiciones manifestadas en el seno de los grupos FISH y COMAR. En la práctica, actuó lealmente al adoptar en sus observaciones una posición neutra sobre la cuestión de la jurisdicción consultiva del TIDM, dado que era consciente de las opiniones divergentes que los Estados miembros mantenían sobre esta cuestión.

\section{CONCLUSIONES}

La participación de la Unión Europea en los sistemas de arreglo de controversias, en particular en los procedimientos ante tribunales internacionales, constituye una materia de creciente importancia en el desarrollo de su acción exterior. Sigue siendo cierto, no obstante, que en términos generales " $[\mathrm{t}] \mathrm{he}$ EU's involvement in international dispute settlement is surronded by a certain number of legal problems and uncertainties» ${ }^{105}$. Al igual que sucede en el marco de la tendencia simultánea a reforzar su participación en las instituciones y foros internacionales — art. 220 TFUE_, tales limitaciones se derivan de un desarrollo insuficiente tanto de las normas del Derecho Internacional general como de las normas del derecho de la Unión, adecuado para atender a las peculiaridades propias de su subjetividad internacional en tanto que organización internacional de integración.

En este contexto, las disposiciones de la sección 2 de la parte XV de la CNUDM ofrecen un modelo de arreglo jurisdiccional de controversias que incluye varias disposiciones específicas sobre la participación de la UE, posteriormente desarrolladas en el Reglamento del TIDM. Aunque dichas disposiciones se muestran insuficientes en diversos aspectos —así sucede, por ejemplo, con las previsiones del art. 7 (3) del Anexo IX sobre la determinación del procedimiento aplicable en los casos en que la Unión y los Estados miembros sean partes conjuntas en una controversia o partes con un mismo interés - su relevancia merece ser destacada. Así, la legitimación y posición reconocidas a la UE en los procedimientos ante el TIDM contrasta con las limitaciones que figuran en el Estatuto de la CIJ con carácter general para las organizaciones internacionales; en particular, las relativas a la participación de las organizaciones internacionales en los procedimientos de carácter contencioso.

105 ROSAS, op. cit., nota 2, p. 321. 
Aunque la práctica de la Unión Europea y los Estados miembros ante el TIDM puede considerarse aún limitada, ha sido suficiente para poner a prueba el equilibrio en las relaciones entre la UE y los Estados miembros, así como el equilibrio institucional y el principio de la unidad en la representación internacional de la Unión en los procedimientos ante órganos judiciales internacionales. Como es posible prever que la participación de la Unión y los Estados miembros en dichos procedimientos seguirá incrementándose, estas cuestiones tenderán a alcanzar en el futuro una mayor complejidad. En el caso del contencioso planteado por el Consejo en relación con la participación de la UE en el procedimiento consultivo ante el TIDM (asunto núm. 21), el Tribunal de Justicia ha podido ofrecer una respuesta basada en el recurso al principio general consagrado en el art. 335 TFUE y en la invocación genérica del principio de cooperación leal consagrado en el art. 13 (2) TUE, para finalmente reafirmar la función de la Comisión en la representación de la UE en los procedimientos ante órganos judiciales internacionales así como su obligación de consultar previamente al Consejo cuando se proponga expresar posiciones en nombre de la UE en el marco de un procedimiento ante un tribunal internacional. Sin embargo, no está claro si en el futuro estas bases jurídicas serán suficientes para enfrentar situaciones eventualmente más complejas, como sucedería en los casos en los que un menor grado de desarrollo normativo en el derecho de la Unión de las materias objeto de un procedimiento ante un tribunal internacional hiciera menos evidente la distinción entre la definición de una política en el sentido del art. 16 (1) TUE y la presentación por la Comisión de un conjunto de apreciaciones jurídicas características de la participación en un procedimiento ante un órgano jurisdiccional ${ }^{106}$.

Adicionalmente, cabe igualmente advertir, que la relevancia teórica y práctica de las cuestiones que suscita la definición de la posición de la UE en los procedimientos ante tribunales internacionales no se limita a su dimensión constitucional interna. Cuando se trata de determinar las modalidades apropiadas de cooperación entre los Estados miembros y la UE, y entre las propias instituciones, con el fin de garantizar de la forma más eficaz la defensa de sus intereses ante los tribunales internacionales, deben tenerse en cuenta las exigencias relativas al cumplimiento de los plazos y la estabilidad del proceso

${ }^{106}$ SÁNCHEZ TABERNERO, op. cit., nota 87. 
como interés común de las partes litigantes o intervinientes en un procedimiento consultivo ${ }^{107}$.

${ }^{107}$ Considerando el ejemplo de la gestión interna de las controversias suscitadas en el marco de la OMC, se ha observado que: «les impératif de célérité imposée par le mécanisme de règlement des différends — qui fait que l'Union européenne ne peut se permettre une éventuel désaccord entre ses institutions- et la nécessité de garantir l'unité de la représentation extérieure - dont la Comission a la charge — ont fait que cette dernière s'est, dans la pratique, rapidement imposée comme l'organe prédominant et ce, même si une autre option permettant l'association du Conseil et du Parlement à la procédure interne était envisageable. Ainsi, jusqu’à aujourd'hui et à l'exception de l'affaire Helms Burtom, la Commission décide de l'opportunité de saisir un groupe spécial dans une affaire. Dès lors, c'est uniquement lorsque la sensibilité politique du différend est saillante que la coopération avec les autres institutions, et notamment le Conseil, s'impose pour la Commission. Cette approche demeure dans la logique de ce qui se déroule au sein d'autres instances, comme par exemple dans le cadre de la Convention des Nations Unies sur le droit de la mer relatives à la conservation e à la gestion de stocks de poissons, et dans laquelle le Conseil apparaît largement en retrait» (TOMKIEWICZ, op. cit., nota 5, pp. 196-197). 